\title{
Profiling the New Immigrant Worker: The Effects of Skin Color and Height
}

\author{
Joni Hersch, Vanderbilt University
}

\begin{abstract}
Using data from the New Immigrant Survey 2003, this article shows that skin color and height affect wages among new lawful immigrants to the United States, controlling for education, English language proficiency, occupation in source country, family background, ethnicity, race, and country of birth. Immigrants with the lightest skin color earn on average $17 \%$ more than comparable immigrants with the darkest skin color. Taller immigrants have higher wages, but weight does not affect wages. Controls for extensive current labor market characteristics that may be influenced by discrimination do not eliminate the negative effect of darker skin color on wages.
\end{abstract}

\section{Introduction}

Prior to the passage of the Immigration Act of 1965, immigrants to the United States were primarily from northern and western Europe. ${ }^{1}$ Indeed, various laws prohibited immigration of Asians and imposed quotas on the number of immigrants from individual countries. For example, the Immigration Act of 1924 was passed to limit the number of immigrants from eastern and southern Europe, who began immigrating in large num-

Many thanks to Eli Berman, William Darity, Arthur Goldsmith, Guillermina Jasso, Jennifer Martin, Amy Nickens, Cordelia Reimers, W. Kip Viscusi, Shelley White-Means, seminar participants at Vanderbilt Law School, and participants at the 2006 Society of Labor Economists annual meeting, the 2007 American Association for the Advancement of Science annual conference, and the 2007 Ohio State University Kirwan Institute for the Study of Race and Ethnicity conference for their helpful comments. Contact the author at joni.hersch@vanderbilt.edu.

${ }^{1}$ Bernard (1980) surveys the history of immigration to the United States and U.S. policy responses with respect to immigration.

[Journal of Labor Economics, 2008, vol. 26, no. 2]

(C) 2008 by The University of Chicago. All rights reserved. 0734-306X/2008/2602-0005\$10.00 
bers in the late nineteenth century. There is substantial historical documentation of discrimination against these new immigrants. ${ }^{2}$ The post-1965 immigrants are primarily from Asia and Latin America, and concerns about discrimination have again been expressed. As with immigrants from eastern and southern Europe a century ago, most new legal immigrants to the United States have darker skin color than white U.S. natives and are on average shorter. This article considers whether skin color and height affect economic outcomes among new legal immigrants to the United States.

To examine this question, I use data from the New Immigrant Survey (NIS) 2003. This survey provides extensive information on a large sample of new lawful immigrants to the United States and also provides uniquely available information on skin color for immigrants. I find strong evidence that darker skin color is associated with lower wages, taking into account a wide array of demographic and productivity-related characteristics such as English language proficiency, education, occupation before migrating to the United States, and family background, as well as ethnicity, race, and country of origin, which are themselves highly correlated with skin color. Immigrants with the lightest skin color earn on average $17 \%$ more than comparable immigrants with the darkest skin color. On average, moving from the 10th percentile to the 90th percentile of the distribution of skin color within ethnic or racial groups would reduce wages by about $7 \%-9 \%$. These magnitudes are roughly similar to the black-white disparity and Hispanic-non-Hispanic disparity reported in Altonji and Blank (1999, table 4).

Notably, skin color continues to influence wages, even when current labor market factors that may be influenced by discrimination, such as occupation, are also taken into account. These results show that immigrants with the lightest skin color earn on average $11 \%$ more than comparable immigrants with the darkest skin color.

Height, which may have a direct productivity effect, is also correlated with skin color. With the exception of immigrants from countries that have majority black populations, immigrants from countries with darker average skin color are considerably shorter on average than the nonHispanic white U.S. population, and there is an inverse relation by country between height and skin color darkness. Failure to also control for height could thereby spuriously lead to a negative effect of skin color on wages. I find that height has an independent effect on wages, with each extra inch of height above the U.S. average associated with a $2 \%$ increase in

\footnotetext{
${ }^{2}$ See, e.g., Hirschman (2005) for a discussion of discrimination faced by immigrants from eastern and southern Europe in the late nineteenth and early twentieth centuries.
} 
wages. In contrast to skin color and height, body weight has no effect on wages.

This article explores the differential incidence of wage disparities based on observable physical characteristics, particularly skin color and height, that differ on average from the U.S. population and consequently may serve to signal foreign appearance. ${ }^{3}$ Even controlling extensively for personal and market characteristics, darker skin color has an independent adverse effect on wages of new legal immigrants.

\section{Background on Skin Color}

Skin color is the most variable of human physical characteristics. ${ }^{4}$ Most genetic markers and physical characteristics show little variation among human populations. In contrast, skin color shows great variation in response to exposure to ultraviolet radiation.

Darker skin close to the equator appears to have been selected to prevent skin cancer, sunburn, the photolysis of folate (a water-soluble B vitamin), and damage to sweat glands, while a leading hypothesis for lighter skin at higher latitudes is that lighter skin allows adequate absorption of ultraviolet rays to promote vitamin $\mathrm{D}$ formation and prevent rickets. ${ }^{5}$ Skin color is lighter in infants than in adults, and, even when not observable by sight, skin color is lighter in females than in males within all indigenous populations. $^{6}$

Although skin color is often considered a proxy for race, race is typically considered to be a social or cultural construct rather than one in-

${ }^{3}$ Evidence of discrimination against U.S. citizens and legal aliens on the basis of "foreign appearance" is documented in the 1990 U.S. General Accounting Office (GAO) report. Using both an employer survey and an audit study, the GAO determined that after the passage of the Immigration Reform and Control Act of 1986 (IRCA), there was widespread discrimination on the basis of foreign appearance that had the greatest impact on those of Hispanic or Asian origin.

${ }^{4}$ For valuable overviews of the scientific literature on skin color, see Jablonski (2006) and the review article by the Race, Ethnicity, and Genetics Working Group, National Human Genome Research Institute (2005).

${ }^{5}$ The gene or genes responsible for skin color variation have not yet been discovered, although the recent discovery that a gene governing a light-colored version of zebra fish has a counterpart in the genome of European people represents an important breakthrough in potentially identifying the genetic basis of skin color (Lamason et al. 2005). I thank Keith C. Cheng for calling this research, which was conducted in his lab at Penn State, to my attention.

${ }^{6}$ Jablonski (2006) summarizes the main hypotheses for this gender disparity: that by imitation of the lighter skin color of infants, females gain social protection; males view lighter-colored females as more feminine and preferable as sexual partners; and darker-colored males are favored to safeguard sperm production. Jablonski's theory is that the lighter skin color of females increases vitamin D levels, which in turn assists in calcium absorption necessary to build the skeleton of the fetus and newborn. 
formative of distinctions among population groups. In fact, researchers have argued for elimination of racial or ethnic categories as a variable in most biomedical, epidemiologic, or public health research.' Jablonski (2006) notes, "Dark skin or light skin, therefore, tells us about the nature of the past environments in which people lived, but skin color itself is useless as a marker of racial identity" (95).

A number of studies based on U.S. data have found empirical support for the premise that skin color affects socioeconomic outcomes among minority populations. ${ }^{8}$ The bulk of the research on skin color has examined African Americans, with a smaller literature examining Hispanics/ Latinos. There is much historical evidence of preferential treatment in the United States of blacks with lighter skin color. ${ }^{9}$ Two national data sets include skin color for African Americans reported by interviewer observation as well as individual earnings information. The National Survey of Black Americans 1979-80 (NSBA) includes skin color reported in five categories, and the Multi-City Study of Urban Inequality 1992-94 (MCSUI) includes skin color reported in three categories. Notable articles by Hughes and Hertel (1990) and Keith and Herring (1991) document preferential outcomes in education, personal and family income, and occupational prestige among those African Americans with lighter skin color, based on data from the NSBA.

Recent studies also using the NSBA, augmented by data from the MCSUI, show a more mixed picture of the earnings effects. Hersch (2006) finds consistent evidence that darker skin tone is associated with lower educational attainment among African Americans, although this study shows limited evidence that lighter skin color is associated with higher wages. Goldsmith, Hamilton, and Darity $(2006,2007)$ find support for a wage advantage to light skin color among African American males. ${ }^{10}$

${ }^{7}$ In 2006 the Journal of Law, Medicine, and Ethics (vol. 34, no. 3) published a symposium issue exploring whether race and ethnic categories should be used in biomedical, epidemiologic, or public health research. See the introduction by Wolf (2006) for an overview.

${ }^{8}$ In addition, there is empirical evidence that skin color affects health outcomes. Darker skin color has been linked to higher blood pressure among people of African descent. See, e.g., Klag et al. (1991), Klonoff and Landrine (2000), and Gravlee, Dressler, and Bernard (2005) and references cited therein.

${ }^{9}$ See, e.g., Russell, Wilson, and Hall (1992), who describe the role of skin color in the status of African Americans in the United States, and Bodenhorn (2003) for an analysis of skin color in the nineteenth-century rural United States.

${ }^{10} \mathrm{In}$ addition to the NSBA and MCSUI, skin color for African Americans is recorded in the 1975 and 1995 waves of the Detroit Area Study and for an oversample of African Americans in the 1982 General Social Survey (GSS). These data sets do not provide information on individual earnings and so cannot be used to investigate whether skin color affects earnings. Studies offering superior measures of skin color, such as the Coronary Artery Risk Development in Young Adults (CARDIA) study, report no information on individual earnings or other 
Two national surveys, the 1979 National Chicano Survey and the 1990 Latino National Political Survey (LNPS), record skin color by interviewer observation reported in five categories for samples of Latinos. Using both data sets, Mason (2004) documents that Mexican Americans with darker skin color have lower earnings. The effect of skin color on earnings for Puerto Ricans and Cuban Americans is mixed and varies by nativity. Using the LNPS, Espino and Franz (2002) provide evidence that lighter skin color is associated with higher occupational prestige among Mexican Americans and Cuban Americans employed in the United States but not among Puerto Ricans.

While the perception that a preference for lighter skin is pervasive in other countries seems to be widely accepted, particularly with regard to India, Asia, Africa, and Central and South America, empirical evidence that gradations of skin color affect economic outcomes outside of the United States appears to be nonexistent. In part, the absence of empirical evidence would derive from the absence of data. The perception that skin color discrimination is pervasive in other countries seems to stem from case studies and from evidence on sales of skin-lightening products. For example, Ehrlich (1977) describes studies that show that gradations of skin color affected legal rights in Spanish colonies and remain an important distinction among Filipinos. Ehrlich also notes that gradations of skin color are important in India and Latin America. Herring (2004) summarizes evidence of preferential treatment of lighter-skinned Latinos that dates to the conquest of the Americas by European powers, with favoritism shown to those in Latin America who had European coloring with respect to skin, eyes, and hair. Hall (1995) summarizes evidence of discrimination against darker-skinned Indian Hindus, with light-skinned wives so preferred that Hindu males will marry light-skinned women from a lower caste. Anthropologists estimate that skin color is a determinant of beauty in 51 of 312 cultures worldwide, with lighter skin preferred over darker skin in all but four of the 51 cultures (Burke and Embrich 2008). A number of news articles describe the large market for skin-lightening products, which may support the perception that lighter skin confers advantages. ${ }^{11}$

The effects of height and weight on economic outcomes have received

economic information. For example, see Krieger, Sidney, and Coakley (1998) for a description of the CARDIA data and an analysis of the relation between skin color and self-reported experiences of racial discrimination.

${ }^{11}$ Timmons (2007) reports that skin-lightening products, such as the Unilever product called Fair and Lovely, are by far the most popular skin care products in India and also notes the large market for skin-lightening products in Korea, Japan, and China, as well as in the United States. Skin-lightening products contain hydroquinone, a carcinogen that breaks down melanin, and are known to damage skin and leave permanent dark spots if used in high doses. 
considerable attention among economists. Historically and in less developed countries, height and weight reflect health status (Steckel 1995; Fogel and Costa 1997). A number of empirical studies using recent data find a height premium in the United States and other countries (e.g., Loh 1993; Thomas and Strauss 1997; Schultz 2002). Possible mechanisms underlying the height advantage include social or psychological factors (Persico, Postlewaite, and Silverman 2004) or greater intelligence (Case and Paxson 2006).

Excess weight may affect earnings by lowering productivity, perhaps via lower health status or via discriminatory treatment of heavier individuals. While the positive effect of height on earnings is well documented, evidence of whether weight affects earnings in the United States is mixed, showing variously that weight has no effect on earnings, an effect that differs by sex or race, or an effect only among those who are obese. For example, Cawley (2004) finds that obesity has a negative effect on earnings only among white women and that weight otherwise has no effect on earnings for men or for other ethnic groups. Both Loh (1993) and Thomas and Strauss (1997) find that weight has a positive effect on wages for males and no effect for females. Hamermesh and Biddle (1994) find no effect of weight on wages.

\section{Empirical Motivation}

The focus of this article is on wage equation estimates. All individuals in the data set have achieved lawful permanent resident status, and all but a handful have relocated to the United States, so the migration decision is not analyzed. But, to motivate the empirical specification, it is useful to start by considering the decision to migrate to the United States. ${ }^{12}$ The mix of immigrants who migrate to the United States from a particular country will depend on the economic benefits of relocating to the United States and the costs of migration. Let $X_{i}$ be a vector of individual $i$ 's characteristics that affect wages in the source country, including market characteristics such as occupation in the source country, as well as human capital and demographic characteristics such as education, age, height, weight, and ethnicity or race. The source country wage for person $i$ in country $j$ is given by $h_{j}\left(X_{i}\right)$. Let $S_{i}$ be the individual's skin color, where higher values of $S$ denote darker skin color. The level of $S_{i}$ may affect source country employment opportunities and educational attainment. If $S_{i}$ affects treatment in the source country, we assume that such treatment is reflected in the components of $X_{i}$, although the analysis is unaffected if we assume skin color has a direct effect on source country wage.

The individual's personal situation and source country will affect the

${ }^{12}$ For an overview of the literature on the migration decision, see, e.g., Borjas (1994). 
costs of migration $c_{j}\left(X_{i}\right)$. Costs of migration vary by factors such as geographical distance from source country to destination country, quotas that affect waiting time, and whether the individual has family members at the destination (Clark, Hatton, and Williamson 2007).

Assume that individual $i$ faces an equilibrium market wage locus in the United States given by $w\left(X_{i}, Z_{i}, S_{i}\right)$, where $Z_{i}$ is a vector of person $i$ 's market skills valued in the U.S. labor market. Because skill characteristics of immigrants depend on factors that may vary by source country, such as quality of education, $Z_{i}$ includes country of birth indicators to control for skill characteristics that are country specific (e.g., Borjas 1995; Bleakley and Chin 2004; Card 2005).

Individual $i$ chooses to migrate from country $j$ if $w\left(X_{i}, Z_{i}, S_{i}\right)-b_{j}\left(X_{i}\right)>$ $c_{j}\left(X_{i}\right)$. The empirical analysis takes as given the migration decision and controls for all observed predetermined labor market characteristics through the vector $X_{i}$ and components of $Z_{i}$ that are exogenous to the process of discrimination under study. That the immigrant population is not a random sample is not a problem because the object of the inquiry is not to determine what a randomly selected worker from a particular country would earn in the United States. This article focuses on the determinants of the labor market equilibrium wage schedule $w(X, Z, S)$. This focus is analogous to that of the hedonic labor market model.

Conditional on employment in the United States, I estimate a conventional $\log$ wage equation of the following general form:

$$
\text { ln wage }=X \beta+Z \delta+\gamma S+\varepsilon .
$$

The dependent variable is the $\log$ of hourly wage. Skin color $S$ is assumed to be unrelated to worker productivity, but discrimination in the United States would lead to lower pay for those with darker skin color for individuals with equal productivity characteristics. A negative coefficient on $S$ is therefore evidence consistent with skin color discrimination. Although skin color is highly correlated with ethnicity, race, and nationality, to the extent that any discrimination faced within the United States is based on ethnicity, race, or nationality rather than on gradations of skin color, inclusion of indicators for ethnicity, race, and country of birth in addition to skin color allows the influence of skin color to be isolated. Note that controlling for these highly correlated characteristics inherently raises the prospect that multicollinearity will influence the precision of any estimate of the extent of the skin color effect on wages.

How one would interpret an effect of $S$ on wages depends on the underlying model of discrimination. Based on the Becker (1957/1971) taste model of discrimination, the preferences of employers, coworkers, or consumers for workers with lighter skin color could lead to lower wages for those with darker skin color. Models of statistical discrimination would hypothesize that employers will use observable characteristics such 
as skin color to form estimates of the worker's productivity. In this context, employers might use observable characteristics in making inferences about the immigrant's legal status. The U.S. GAO (1990) study found that $5 \%$ of employers "began a practice, as a result of IRCA, not to hire job applicants whose foreign appearance or accent led them to suspect that they might be unauthorized aliens" (6). Inferences about legal status, even if wrong, may result in lower wage offers to those with a foreign appearance. Valuable reviews of the theory and evidence of discrimination on the basis of race and sex are provided in Cain (1986) and Altonji and Blank (1999).

As in any analysis of discrimination, $X$ and $Z$ are presumed to contain only productivity characteristics that are exogenous to the process of discrimination under study. However, as a check for robustness and generality of the findings, I additionally present estimates with current U.S. market characteristics such as occupation and self-employment status. Such characteristics may be influenced by any skin color discrimination and, if so, may be endogenously determined with the wage.

\section{The New Immigrant Survey 2003}

The NIS provides a nationally representative sample of immigrants admitted to lawful permanent resident status, drawn from electronic files compiled by the U.S. government. ${ }^{13}$ The sampling design includes a sample of adults, who are 18 years or older, and a child sample. A pilot survey was fielded in 1996. I use the first full adult sample cohort of the NIS, known as the NIS 2003, which includes a sample of 8,573 adult respondents admitted to lawful permanent resident status during the 7-month period May-November 2003. Respondents provide information on a wide range of topics, including detailed labor market information.

Immigrants who meet the eligibility criteria for admission to lawful permanent resident status (e.g., spouses of U.S. citizens and employment preference) are called principals. Accompanying spouses and minor children in certain classes of admission (e.g., spouses and minor children of

${ }^{13}$ The following description of the NIS is based on Jasso et al. (forthcoming) and the survey overview available at http://nis.princeton.edu/overview.html. The data and documentation are available at http://nis.princeton.edu. The survey was initiated by the principal investigators named above and supported by the National Institutes of Health; National Science Foundation; U.S. Citizenship and Naturalization Service; the assistant secretary for planning and evaluation, U.S. Department of Health and Human Services; and the Pew Charitable Trusts. The data collection was performed by professional survey staff from the National Opinion Research Center (NORC). NORC has had prior experience with skin color ratings, as they also collect the GSS data, which include interviewer rating of skin color for the oversample of African Americans in the 1982 wave. The field work was conducted between June 2003 and June 2004. I include in the wage analyses an indicator for year to control for price increases. 
employment principals) are also granted visas. The sampling frame for the adult sample covers adult immigrants who have visas as principals or as accompanying spouses. In the design of the sampling frame, there are four sampling strata reflecting the methods available to reach lawful permanent resident status. These four strata are composed of spouses of U.S. citizens, employment-visa principals, diversity-visa principals (who are granted a visa via lottery), and all other immigrants. The sampling design oversamples employment-visa and diversity-visa principals and undersamples spouses of U.S. citizens. Jasso et al. (forthcoming) report a response rate of at least $68.6 \%$ for the NIS $2003 .{ }^{14}$ The NIS 2003 provides sample weights to account for the sampling design. To account for differences in response rates by strata, I adjust the sample weights for response rates within strata and use these weights throughout to account for sample design and response rates for all statistics and regression results reported in this article. ${ }^{15}$

${ }^{14}$ Nonresponse to the NIS 2003 does not seem to be a problem for any particular group. The NIS survey team has not yet conducted a formal analysis of nonresponse, but my review of unofficial statistics provided by project manager Jennifer Martin suggests that nonresponse does not vary in any systematic fashion by visa type or country of birth. The NIS 2003 response rate compares favorably to that of other surveys. The U.S. GAO (1990) employer survey of immigrant practices has a response rate of $69 \%$. The response rate in the NIS 2003 is similar to that of the three studies reporting skin color that have been used to analyze skin color effects among African Americans or Latinos residing in the United States. The response rate for the NSBA $1979-80$ was $67 \%$ (Jackson and Gurin 1997). The response rate for the MCSUI varied by city, with unadjusted response rates of 75\% for Atlanta, 71\% for Boston, 78\% for Detroit, and $68 \%$ for Los Angeles (Bobo et al. 2000). The response rate in the LNPS was 74\% for Latinos and $56 \%$ among non-Latinos (de la Garza et al. 1998). Holbrook, Krosnick, and Pfent (2007) provide a valuable literature review and analysis of response rates to over 100 random-digit-dialing telephone surveys conducted over a 10 -year period by leading survey organizations, including surveys conducted for the U.S. government. Although it is conventionally believed that high response rates are indicative of a representative sample, their literature survey shows mixed evidence of a relation between response rates and whether the survey sample is representative of the population. Their analysis also shows that response rates to telephone surveys range from $4 \%$ to $70 \%$ and averages $30 \%$, with declining response rates to telephone surveys over time. The Office of Management and Budget (OMB) Standards and Guidelines for Statistical Surveys provides guidelines for censuses and surveys conducted by federal agencies (available at http://www.whitehouse .gov/omb/inforeg/statpolicy/standards_stat_surveys.pdf). The OMB recognizes the inherent trade-off between data collection costs and response rates and recommends planning for a nonresponse bias analysis for surveys with response rates below $80 \%$. Finally, for comparison to an ongoing U.S. government survey, the response rate for the American Time Use Survey for 2006 is 55.1\% (see http:// www.bls.gov/tus/atususersguide.pdf).

${ }^{15}$ Response rates by strata are reported at http://nis.princeton.edu/downloads/ nis_2003/NIS-2003-Sampling-Weights.pdf. Because response rates across strata 
Immigrants were interviewed as soon as possible after achieving lawful permanent resident status. Respondents were located by the addresses at which their green cards were sent; the actual states are identified in the public use data for respondents in California, Florida, Illinois, New Jersey, New York, and Texas, with all others assigned to their census region. All respondents were interviewed in the language of their choice, with interviews conducted in over 80 languages. The sample includes 321 individuals who had achieved lawful permanent resident status but had not relocated to the United States as of the time they were interviewed. All such immigrants were interviewed by telephone. Interviews for those residing in the United States were either conducted in person or partly in person and partly by telephone.

Skin color is not recorded for interviews that were conducted exclusively by telephone and is not always recorded for interviews that were completed by telephone, so there are a large number of missing values for skin color. Of the full sample of 8,573 observations, skin color is recorded for 4,652 respondents. ${ }^{16}$

Before turning to the wage equation estimates, this section defines the skin color measure and provides information on skin color, height, weight, and the relation of these characteristics to country of birth and Hispanic ethnicity and race, for all respondents to the NIS 2003. Country of birth is reported for all respondents in the U.S. government electronic files from which the NIS sample is drawn, but only 22 countries are separately identified (including the United States) in the public use data, with the remaining countries grouped by broad region. ${ }^{17}$ Table 1 characterizes the country or region of birth for the full sample grouped into four categories: majority Hispanic, regardless of race; majority Asian; majority black; and majority non-Hispanic white. The vast majority of the NIS 2003 survey respondents are from countries with majority Hispanic or Asian populations, with $41 \%$ from countries with a majority Hispanic population, $29 \%$ from countries with a majority Asian population, $10 \%$ from countries with a majority black population, and $20 \%$ from countries with a majority white population.

are very similar, all statistics and regression results are virtually identical using either sample design weights or sample weights adjusted for response rates.

${ }^{16}$ I also constructed weights to account for differences by strata in whether skin color is reported. Because the probability that skin color is reported is similar across strata, all statistics and regression results are virtually identical, using weights adjusted for sample design and response rates or weights additionally adjusted for whether skin color is reported. I present the results based on weights adjusted for sample design and response rates to ease comparisons with studies using the NIS 2003 data that do not involve skin color.

${ }^{17}$ Seventy percent of the respondents are from countries that are specifically identified. There are six broad regions such as Middle East and North Africa, or Europe and Central Asia. 
Table 1

Racial and Hispanic Composition by Country or Region

\begin{tabular}{|c|c|c|c|}
\hline & \% White & $\%$ Hispanic & $N$ \\
\hline \multicolumn{4}{|c|}{ Majority Hispanic country or region: } \\
\hline Ćolombia & 90.2 & 97.9 & 133 \\
\hline Cuba & 92.9 & 99.6 & 145 \\
\hline Dominican Republic & 64.1 & 97.2 & 167 \\
\hline El Salvador & 76.5 & 97.0 & 484 \\
\hline Guatemala & 78.9 & 97.1 & 189 \\
\hline Mexico & 74.5 & 97.1 & 1,164 \\
\hline Peru & 80.4 & 98.9 & 113 \\
\hline \multirow[t]{2}{*}{ Latin America, Caribbean } & 61.3 & 66.9 & 499 \\
\hline & $\%$ Asian & $\%$ Hispanic & $N$ \\
\hline \multicolumn{4}{|l|}{ Majority Asian country or region: } \\
\hline Peoples Republic of China & 99.5 & .0 & 476 \\
\hline India & 90.3 & .1 & 773 \\
\hline Korea & 100.0 & .0 & 144 \\
\hline Philippines & 92.1 & 5.9 & 512 \\
\hline Vietnam & 100.0 & .5 & 223 \\
\hline \multirow[t]{2}{*}{ East Asia, South Asia, Pacific } & 91.5 & .8 & 589 \\
\hline & $\%$ Black & $\%$ Hispanic & $N$ \\
\hline \multicolumn{4}{|l|}{ Majority black country or region: } \\
\hline Ethiopia & 96.9 & .3 & 199 \\
\hline Haiti & 97.7 & 1.3 & 154 \\
\hline Jamaica & 94.5 & 1.4 & 117 \\
\hline Nigeria & 96.8 & .3 & 173 \\
\hline \multirow[t]{2}{*}{ African sub-Saharan } & 83.7 & 1.3 & 391 \\
\hline & \% White & $\%$ Hispanic & $N$ \\
\hline \multicolumn{4}{|c|}{ Majority non-Hispanic white country or region: } \\
\hline Canada & 90.0 & .0 & 103 \\
\hline Poland & 100.0 & 1.7 & 196 \\
\hline Russia & 100.0 & .5 & 121 \\
\hline Ukraine & 99.7 & .0 & 144 \\
\hline United Kingdom & 81.8 & .0 & 102 \\
\hline Europe, Central Asia & 96.7 & 1.4 & 820 \\
\hline Middle East, North Africa & 75.6 & 2.1 & 391 \\
\hline Oceania & 97.5 & 2.5 & 31 \\
\hline
\end{tabular}

Regardless of country of birth, respondents are asked whether they consider themselves to be Hispanic or Latino. They are also asked to indicate which race or races they consider themselves to be, with multiple racial categories recorded. The racial group options are American Indian or Alaska native, Asian, black, native Hawaiian or other Pacific Islander, and white. As table 1 shows, with the exception of the United Kingdom and the broad groupings of Latin America and the Caribbean, African sub-Saharan, and the Middle East and North Africa, at least $90 \%$ of the immigrants from each country report themselves to be Hispanic or of a single race. 
The key variable of interest is the unique information on skin color, measured by a scale designed by Massey and Martin (2003). The color scale provided to the interviewers shows a series of hands, numbered from one to 10 , with color increasing in darkness (see app. A). Interviewers were instructed to memorize the skin color scale and report the skin color most closely matching the respondent's color using an 11-point scale ranging from zero to 10 , where zero represents the lightest possible color (e.g., albinism), and 10 represents the darkest possible skin color. ${ }^{18}$ The NIS scale is a clearly demarcated 11-point scale increasing from light to dark, offering a more continuous and specific measure of skin color relative to all other surveys used to examine economic outcomes that record skin color in from three to five categories (e.g., NSBA and MCSUI). The NIS survey also uniquely provides skin color information specifically for immigrants.

Table 2 reports average skin color scores by country or region and by sex. Figure 1 presents a histogram of skin color by sex and shows that the full range of values were used by the interviewers. Figures 2 and 3 provide histograms for skin color pooled by sex by whether the respondent self-reports as Hispanic, Asian, black, or white, where the racial categories are mutually exclusive and disjoint from Hispanic ethnicity. ${ }^{19}$

First, note the apparent reasonableness of the skin color ratings. Respondents self-reporting their race as white are rated overall as the lightest, black respondents as the darkest, and Asians and Hispanics as between whites and blacks. Note also the overlap in the distributions. The histograms show considerable variation in skin color rating, even among respondents with the same self-reported Hispanic ethnicity or race, indicating that interviewers record individual variations in skin color rather than defaulting to a modal value by ethnic or racial group.

The NIS skin color scale has not been validated previously, and an analysis of inter-interviewer reliability has not been conducted. Evidence on the validity of the NIS scale can be provided by comparison to skin color measures obtained by reflectance spectrophotometer, which mea-

${ }^{18}$ Per Guillermina Jasso, NIS survey managers noticed an apparent overuse of the skin color rating of zero by NORC interviewers after fieldwork commenced and issued a memo to clarify that zero should be used to indicate albinism. As recommended in Jasso (2007), I include an indicator variable in the wage analysis to denote whether the interview occurred before or after the date of the memo. Fifty-seven percent of the surveys were conducted after the memo. In part this indicator also picks up price changes over the survey period.

${ }^{19}$ Figures 2 and 3 do not provide the distribution of skin color for respondents in categories with too few observations to be meaningfully represented by a histogram. These are non-Hispanic American Indian or Alaska native (22 observations); native Hawaiian or other Pacific Islander (34 observations); non-Hispanic with multiple races reported (nine observations); and non-Hispanic, no race reported (68 observations). 
Table 2

Characteristics of Skin Color and Height by Country or Region and Sex

\begin{tabular}{|c|c|c|c|c|}
\hline & \multicolumn{2}{|c|}{ Mean Skin Color } & \multicolumn{2}{|c|}{ Mean Height } \\
\hline & Female & Male & Female & Male \\
\hline \multicolumn{5}{|l|}{ Majority Hispanic country or } \\
\hline region & $4.25(1.81)$ & $4.51(1.86)$ & $62.70(3.57)$ & $67.22(3.57)$ \\
\hline Majority Asian country or region & $3.78(1.71)$ & $4.23(1.85)$ & $62.31(2.69)$ & $67.05(3.11)$ \\
\hline Majority black country or region & $6.61(2.27)$ & $7.40(2.11)$ & $64.27(3.86)$ & $68.74(3.79)$ \\
\hline \multicolumn{5}{|l|}{ Majority non-Hispanic white } \\
\hline country or region & $2.42(1.67)$ & $2.58(1.74)$ & $64.80(3.13)$ & $69.91(3.13)$ \\
\hline All observations & $4.03(2.09)$ & $4.36(2.26)$ & $63.12(3.39)$ & $67.96(3.58)$ \\
\hline Number of observations & 2,404 & 2,248 & 3,921 & 3,854 \\
\hline \multicolumn{5}{|l|}{$\begin{array}{l}\text { Majority Hispanic country or } \\
\text { region: }\end{array}$} \\
\hline Colombia & $3.35(2.06)$ & $3.46(1.70)$ & $63.09(2.79)$ & $67.37(2.79)$ \\
\hline Cuba & $3.29(1.71)$ & $3.84(1.70)$ & $63.96(2.78)$ & $68.14(2.71)$ \\
\hline Dominican Republic & $4.54(2.09)$ & $4.87(1.88)$ & $63.55(2.78)$ & $68.05(3.14)$ \\
\hline El Salvador & $4.33(1.59)$ & $4.37(1.79)$ & $61.91(3.86)$ & $66.00(3.58)$ \\
\hline Guatemala & $4.32(1.69)$ & $4.54(1.65)$ & $61.50(4.20)$ & $65.99(3.29)$ \\
\hline Mexico & $4.25(1.67)$ & $4.58(1.60)$ & $62.47(3.54)$ & $67.23(3.74)$ \\
\hline Peru & $4.47(1.62)$ & $3.21(2.08)$ & $62.26(2.90)$ & $68.62(3.63)$ \\
\hline Latin America, Caribbean & $4.66(2.11)$ & $4.94(2.36)$ & $63.77(3.62)$ & $68.00(3.34)$ \\
\hline \multicolumn{5}{|l|}{ Majority Asian country or region: } \\
\hline Peoples Republic of China & $3.66(1.48)$ & $3.32(1.46)$ & $62.55(2.93)$ & $66.96(3.29)$ \\
\hline India & $4.48(2.02)$ & $4.99(2.06)$ & $62.86(2.59)$ & $67.73(3.07)$ \\
\hline Korea & $3.02(1.35)$ & $3.75(1.86)$ & $62.36(1.78)$ & $67.75(1.95)$ \\
\hline Philippines & $3.91(1.79)$ & $4.32(1.87)$ & $61.75(2.27)$ & $66.24(2.73)$ \\
\hline Vietnam & $3.32(1.09)$ & $3.76(1.05)$ & $61.14(3.42)$ & $65.16(2.34)$ \\
\hline East Asia, South Asia, Pacific & $3.58(1.78)$ & $4.57(1.88)$ & $62.51(2.56)$ & $67.38(3.31)$ \\
\hline \multicolumn{5}{|l|}{ Majority black country or region: } \\
\hline Ethiopia & $6.68(2.21)$ & $7.40(1.74)$ & $63.40(3.29)$ & $67.77(2.95)$ \\
\hline Haiti & $5.85(1.63)$ & $6.18(1.82)$ & $63.85(4.02)$ & $67.70(3.87)$ \\
\hline Jamaica & $7.19(1.93)$ & $7.95(1.95)$ & $64.51(2.49)$ & $69.17(3.36)$ \\
\hline Nigeria & $7.33(2.78)$ & $8.32(1.25)$ & $65.24(3.10)$ & $69.93(3.54)$ \\
\hline African sub-Saharan & $6.73(2.59)$ & $7.38(2.47)$ & $64.29(4.66)$ & $68.86(4.16)$ \\
\hline \multicolumn{5}{|l|}{$\begin{array}{l}\text { Majority non-Hispanic white } \\
\text { country or region: }\end{array}$} \\
\hline Canada & $1.68(1.66)$ & $2.42(2.89)$ & $65.18(2.43)$ & $70.65(2.47)$ \\
\hline Poland & $1.94(.68)$ & $1.96(.57)$ & $65.05(2.84)$ & $70.67(2.59)$ \\
\hline Russia & $2.55(1.51)$ & $3.07(1.49)$ & $64.82(2.39)$ & $69.17(2.83)$ \\
\hline Ukraine & $2.56(1.63)$ & $3.15(1.67)$ & $65.21(2.32)$ & $69.83(2.64)$ \\
\hline United Kingdom & $2.41(1.78)$ & $2.58(2.61)$ & $65.36(3.14)$ & $70.47(2.96)$ \\
\hline Europe, Central Asia & $2.33(1.72)$ & $2.16(1.65)$ & $65.10(3.21)$ & $70.15(3.26)$ \\
\hline Middle East, North Africa & $3.10(1.84)$ & $3.27(1.62)$ & $63.40(3.54)$ & $68.82(3.20)$ \\
\hline Oceania & $1.07(.32)$ & $2.04(1.29)$ & $66.10(2.86)$ & $72.54(1.95)$ \\
\hline
\end{tabular}

SOURCE.-Author's calculations using the New Immigrant Survey 2003.

Note.-Standard deviation is in parentheses. All values weighted to account for sample design and response rates.

sures the amount of reflected light. Higher reflectance values indicate lighter skin color. Jablonski and Chaplin (2000) provide a table of skin reflectance for all indigenous populations for which reflectance measures are available..$^{20}$ Nine of the countries represented in the NIS 2003 sample

${ }^{20}$ In Jablonski and Chaplin (2000), indigenous populations are those that "had existed in their current location for a long time prior to European col- 


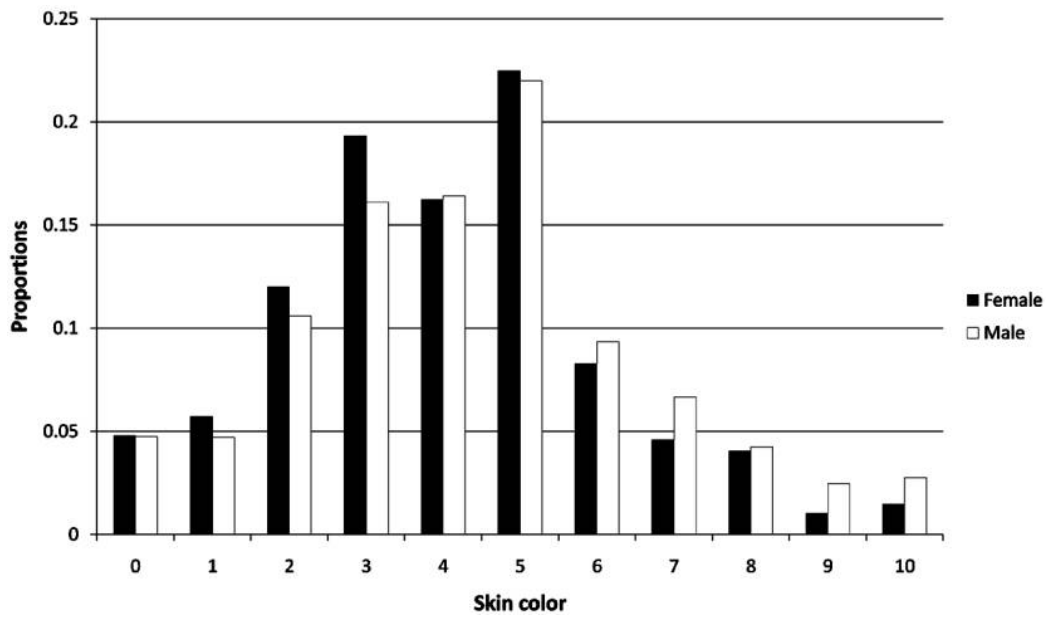

Fig. 1.-Distribution of skin color by sex. All values weighted to account for sample design and response rates. Source: author's calculations using the New Immigrant Survey 2003.

also appear in this table. ${ }^{21}$ Despite differences in methodology, the rank order of skin color using the NIS scale and the observed reflectance value is quite similar, yielding a Spearman's rank correlation coefficient of 0.82 ( $p$-value <.01). If we assume that the NIS 11-point scale can be considered as a cardinal scale instead of an ordinal scale, there is a high degree of concordance between the reflectance measures and the NIS scale, with a Pearson's correlation coefficient of 0.95 ( $p$-value <.01).

Second, as indicated by figure 1 and verified in table 2, within the NIS 2003 sample, women are on average scored as lighter than men and are also scored as lighter in every country except China and Peru and in the broad region of Europe and Central Asia. This pattern is consistent with known

onization." They also exclude "populations known to have high levels of admixture or to have recently migrated to their current location" (65). Jablonski and Chaplin report that the reflectance values are means based on a mixture of males and females and that the sample sizes per country or region vary considerably and range from one to 453 . They do not report individual sample sizes on which these means are based.

${ }^{21}$ The nine countries represented in the NIS sample as well as the reflectance sample are China, Ethiopia, India, Nigeria, Peru, Philippines, Russia, United Kingdom, and Vietnam. For six of these countries, two or more reflectance values are reported corresponding to different populations or regions within countries. For example, nine values are reported for India. To calculate correlation coefficients, I use the median value reported in Jablonski and Chaplin (2000) for each country when more than one value is reported, and I use the mean value of skin color calculated from the NIS, pooling males and females. 

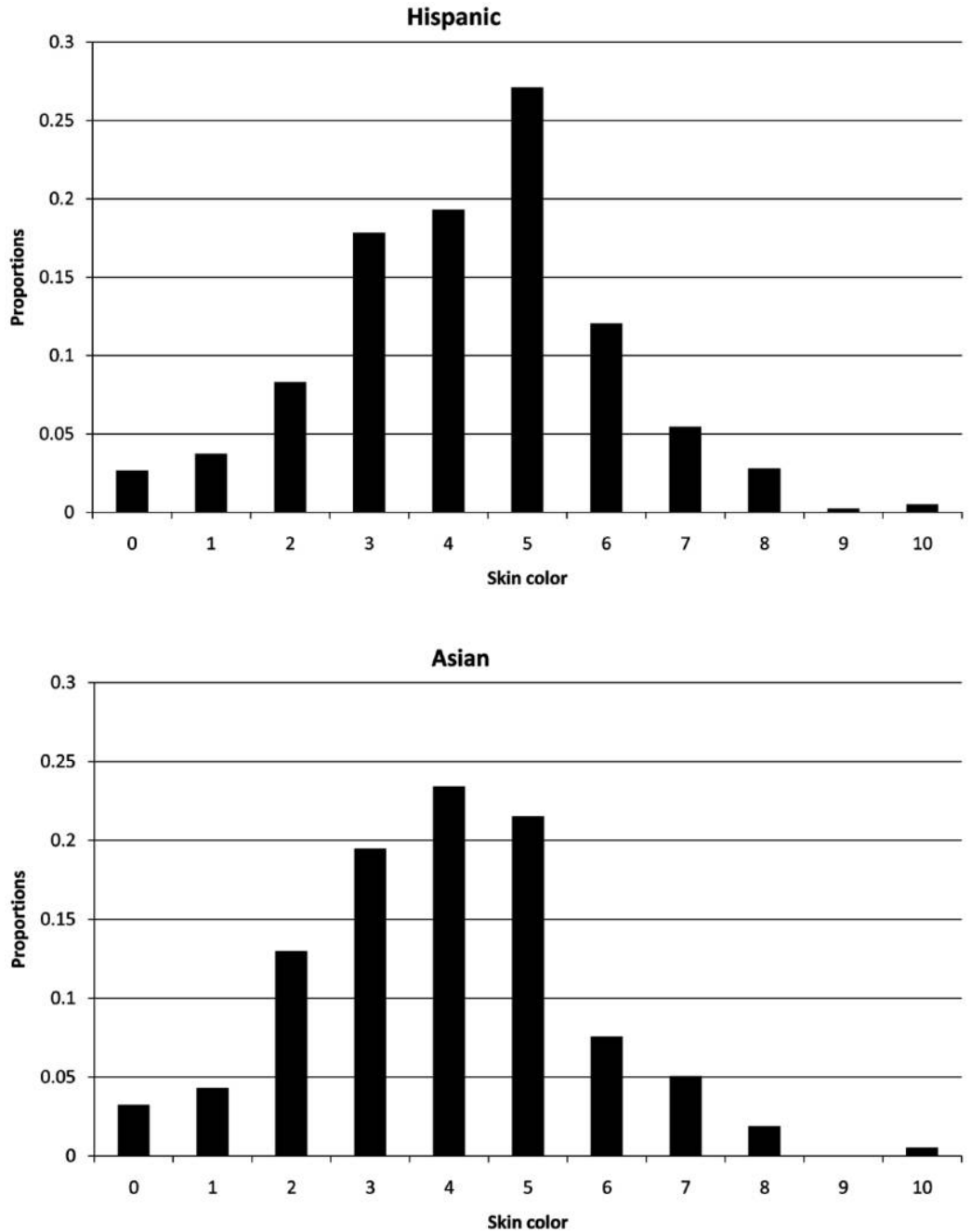

FIG. 2.-Distribution of skin color by ethnicity or race. Number of observations: Hispanic $=1,741$, and Asian $=1,225$. All values weighted to account for sample design and response rates. Source: author's calculations using the New Immigrant Survey 2003.

gender differences in skin color within indigenous populations (Jablonski and Chaplin 2000; Jablonski 2006).

Given the high degree of concordance with the cardinal scale provided by reflectance, treating the NIS scale as a cardinal scale seems reasonable. Furthermore, based on the regression estimates using data from all countries that follow, there is no evidence of nonlinearities in the effect of skin color on wages. Replacing the ordinal skin color measures with indicators 

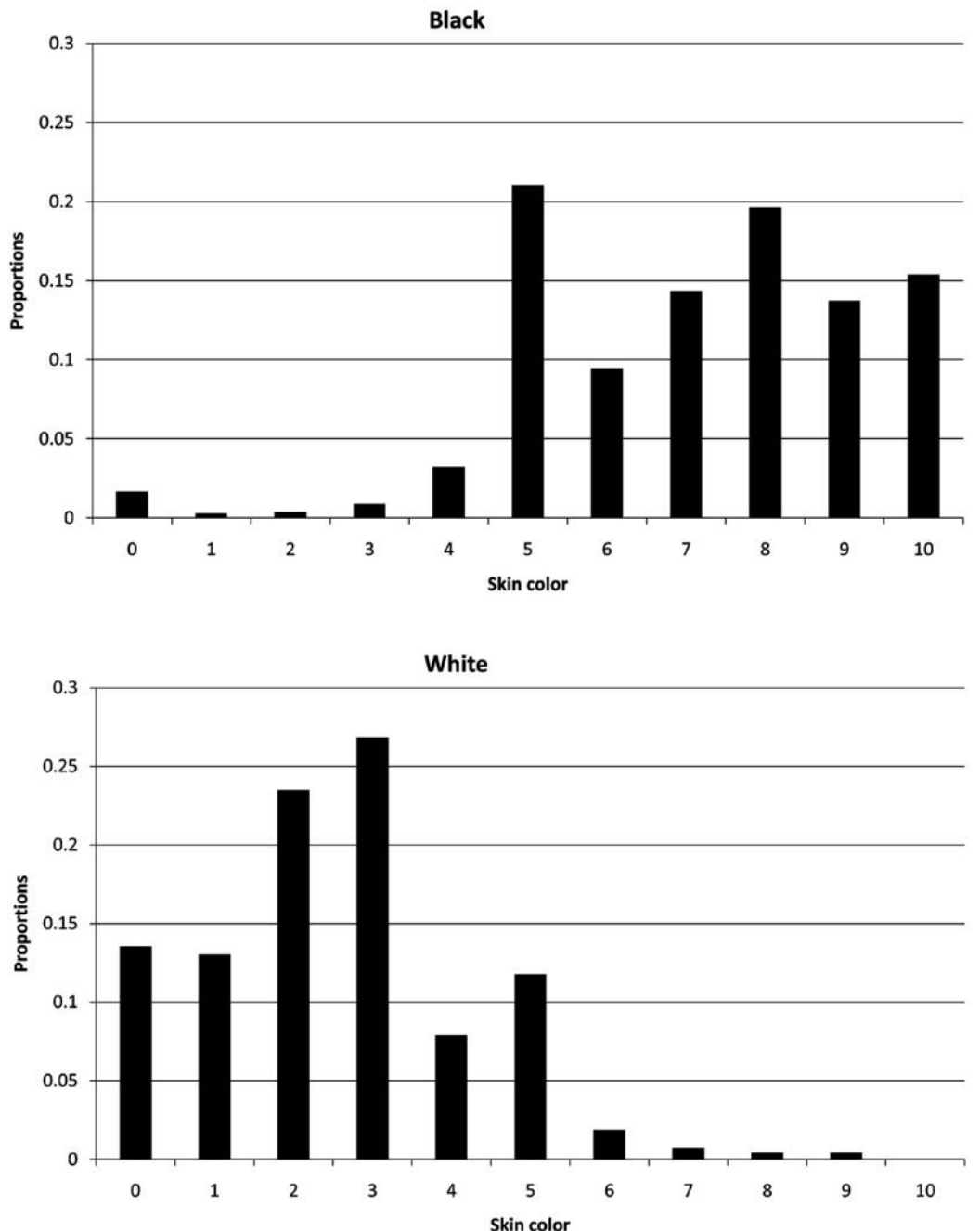

FIG. 3.-Distribution of skin color by ethnicity or race. Number of observations: black $=546$, and white $=1,007$. All values weighted to account for sample design and response rates. Source: author's calculations using the New Immigrant Survey 2003.

for each value of the ordinal measure shows that $F$-tests of the hypothesis that the marginal effects of moving from one category to the next are all equal to each other cannot be rejected in any of the wage equations reported in this article. Therefore, in the remainder of the article, the NIS scale is treated as a cardinal measure.

Because skin color is reported by interviewer observation by reference to a skin color chart, measurement error is of course a possibility. Classical measurement error would bias downward any estimated effect of skin 
color on wages. Although the NORC survey staff is composed of trained professionals, it is still possible that interviewers are themselves biased in assigning skin color ratings. The interviewer instructions note that a reason for collecting skin color data is a concern about discrimination on the basis of skin color. ${ }^{22}$ These instructions may predispose interviewers to report a lighter skin color for those whose socioeconomic status is higher than for those whose socioeconomic status is lower.

However, the high degree of concordance of the NIS skin color ratings with the objective reflectance measures and the consistent reporting of women as lighter than men strongly suggest that reported skin color is not systematically biased. An additional test for interviewer bias is to examine the subsample of respondents who are not working for pay, as interviewers' assignment of skin color ratings cannot be affected by differences in wages. ${ }^{23}$ Comparison of the objective reflectance measures to the NIS 2003 ratings among those not employed produces correlations that are similar to those based on the full skin color sample, with a Spearman's rank correlation coefficient of $0.87(p$-value $<.01)$ and a Pearson's correlation coefficient of 0.97 ( $p$-value $<.01)$. Furthermore, to the extent that interviewers exhibit any bias in reporting as darker those with lower wages, presumably they would base this assessment on the entirety of the individual's situation. Knowledge of family background as well as of the predetermined labor market characteristics such as education, occupation before migration, and so forth, would mitigate any such implicit bias. $^{24}$

22 The Field Interviewer Manual includes the following instruction: "As you know, human beings display a wide variety of physical attributes. One of these is skin color. Unfortunately discrimination on the basis of skin color continues to be a reality in American life. Substantial evidence suggests that lighter skinned people fare better in a variety of social and economic settings than those with darker skins. In order to detect such discrimination, it is important that the NIS include a measure of skin color. We therefore ask interviewers to use the Scale of Skin Color Darkness as a guide to rate the skin color of each respondent on a scale of 0 to 10 , where 0 is the lightest possible skin color (such as that of an albino) and 10 is the darkest possible skin color" (Massey and Martin 2003, 1).

${ }^{23}$ Estimates of whether the probability of employment is affected by skin color, controlling for predetermined variables including demographic information, occupation before migration, and family background, show that skin color is not a significant determinant of the probability of employment.

${ }^{24}$ There seems to be no way to conduct a direct test of interviewer bias, such as by controlling for interviewer fixed effects. First, interviewers were largely matched by language, and to the extent that language and skin color are correlated, interviewers would not see a random sample of cases but instead a sample that would be more similar in skin color. Second, if all interviewers are biased and rate those who have lower wages as darker than they would be perceived by the general population, the skin color effect would be overstated, and controlling for interviewer fixed effects would not address this problem. 
Two other observable physical characteristics that are potentially important in the labor market are height and weight. Respondents report their height using centimeters, meters, feet, inches, or combinations thereof. I convert height to inches for all respondents. Weight is also selfreported in pounds or kilos. Body mass index (BMI) is calculated from information on height and weight. ${ }^{25}$

Table 2 also reports means of height by country or region and by sex. For comparison, the mean height for non-Hispanic white males and females in the United States is 69.8 inches for males and 64.1 inches for females (McDowell et al. 2005). As table 2 demonstrates, immigrants are on average considerably shorter than the non-Hispanic white U.S. population, with male immigrants averaging almost 2 inches shorter and female immigrants averaging 1 inch shorter. Sixty-nine percent of the males in the sample fall below the mean height for non-Hispanic white males in the United States, and $65.5 \%$ of the women in the sample are below the mean height for non-Hispanic white females in the United States.

However, the height of immigrants relative to the non-Hispanic white U.S. average varies considerably by country of birth. Immigrants from countries with majority Hispanic and Asian populations are considerably shorter than the non-Hispanic white U.S. average. For males from the majority Hispanic countries, the average height is 67.2 inches, and $76.9 \%$ are below the non-Hispanic white male average of 69.8 inches. For males from the majority Asian countries, the average height is 67.0 inches, and $80.4 \%$ are below 69.8 inches. A similar pattern holds for women, with $68 \%$ of women from the majority Hispanic countries and $82 \%$ of women from the majority Asian countries below the average for non-Hispanic white females in the United States. In contrast, immigrants from the majority non-Hispanic black or non-Hispanic white countries have average heights similar to the non-Hispanic white U.S. average.

Obesity does not seem to be a particular problem for immigrants in the NIS 2003. Immigrants have an average BMI that is below that of nonHispanic whites in the United States. The mean BMI for non-Hispanic white males is 28.0; for non-Hispanic white females it is 27.7 (McDowell et al. 2005). Within the NIS 2003 sample, the average BMI values are 25.9 for males and 24.6 for females. Furthermore, the low average BMI does

${ }^{25} \mathrm{BMI}$ is calculated as (weight in kilograms/height in meters squared) or equivalently as $703 \times$ (weight in pounds/height in inches squared). Overseas respondents did not report their weight or height, another 213 did not report weight, and 275 did not report height. In addition to these missing values, I set to missing those with weight under 60 pounds or height under 40 inches or greater than 84 inches. Most of the respondents with height set to missing reported their height as 1 meter without, presumably, responding to the second part of the questions asking for additional centimeters. I also set BMI to missing for observations with BMI under 14 (eight observations) or greater than 100 (one observation). 
not arise because immigrants in the sample are unhealthily underweight (Jasso et al. 2005). BMI by country is not reported in table 2 because the wage regressions show that BMI never has a significant effect on wages in various alternative specifications.

There is no information on skin color for the U.S. population comparable to that on height and BMI. As a comparison, consider white immigrants from the majority white countries identified in tables 1 and 2 (excluding the broad grouping of Middle East and North Africa). ${ }^{26}$ The average skin color value among these males is 2.28 , and the average for females is 2.19. These values are considerably below the average skin color value in the sample of 4.36 for males and 4.03 for females, and $80 \%$ of the males and $77 \%$ of the females in the sample have a skin color value above the average for their sex, relative to the sample of white immigrants from the majority white countries.

Finally, there is a correlation between average country skin color and average country height, with a weaker correlation between skin color and BMI. Because there is no known genetic link between individual skin color and height or BMI, nor is there any genetic reason to expect such a link to exist, an analysis at the individual level would not be appropriate. However, historic differences in diet and health could lead to average differences by country in height and weight. A correlation between skin color and height or weight may contribute to stereotyping on the basis of physical characteristics. If height and weight are correlated with skin color, omitting these observable physical traits that may have actual productivity effects could spuriously indicate that skin color has an effect on wages.

The correlations by country indicate that the relation between skin color and height differs by race. Excluding countries with a majority black population, the correlations between average country skin color and average country height is -0.67 ( $p$-value $<.01)$, indicating that the average skin color is darker in countries in which the average height is shorter. There is a weaker positive correlation between skin color and BMI. Excluding the majority black countries, the correlation is 0.39 ( $p$-value $=$ .053). In the five countries with a majority black population, the correlation between average country skin color and average country height is 0.86 ( $p$-value $=.06)$, and the correlation between average country skin color and average country BMI is $-0.14(p$-value $=.82)$.

\footnotetext{
${ }^{26}$ The regional group Middle East and North Africa is excluded from this calculation because it seems likely that some respondents in this regional group, such as those from Algeria and Morocco, would have reported their ethnicity as Arab rather than their race as white, had that option been available.
} 


\section{Wage Equation Estimation: Variable Definitions and Sample Characteristics}

The wage equation estimation proceeds in two stages. I begin with estimates including only demographic, physical, and labor market characteristics acquired before current employment. As such, these are predetermined characteristics that are the least likely to be influenced by discrimination in the United States, although they may be influenced by discrimination in the country of birth. I then add labor market characteristics associated with current employment in the United States, which may be influenced by discrimination.

The variables used in the analyses are defined as follows. Workers paid hourly report their hourly wage rate for regular work, not including extra for overtime. ${ }^{27}$ Those paid salary or other than hourly report their salary and the corresponding time unit. Self-employed workers are asked whether they are paid a regular salary or wage and to report that amount as well as pay period. Those who are self-employed but who are not paid a regular salary or wages are not asked to report earnings and so are not included in the wage analysis, although they are examined later in the investigation of the effect of skin color on the probability of self-employment. I calculate an hourly wage rate for those salaried as well as for those self-employed, from information on hours worked, salary, and pay period. $^{28}$

Skin color, height, and BMI are defined in Section IV. Because height may have a nonlinear effect on wages, and because the bulk of the new legal immigrants in the sample are shorter than the U.S. average, height is included in the wage regressions using two terms: one denoting the

${ }^{27}$ Respondents do not have any reason to overstate their employment or earnings because they fear deportation if they are not productive members of society. All immigrants in the study have legal status and as such have the right to live permanently in the United States as long as they do not commit any actions that would make them deportable under section 237 of the Immigration and Nationality Act. These actions are not tied to earnings or employment but refer strictly to activities such as obtaining legal status fraudulently or committing crimes. It is likely that immigrants who have achieved legal status are aware of this right and do not feel they need to misrepresent their employment or earnings.

${ }^{28}$ The survey instrument does not specify whether respondents should report bonuses, if any. Also of possible relevance is the calculated hourly wage for those salaried or self-employed who report that their hours vary, if varying hours are systematically related to skin color and introduce systematic rather than random error in calculated wage. An analysis of the data shows no link between varying hours and skin color, so there is no reason to be concerned that the wage equation estimates are biased in this fashion. Wage equations controlling for variable hours show a positive effect of variable hours on wages, possibly as a compensating differential, but inclusion of variable hours has almost no effect on the coefficient on skin color or any other results. 
number of inches below the U.S. gender-specific average for those below the average and the other denoting the inches above the U.S. genderspecific average for those above the average. To the extent that the physical environment is designed for the characteristics of the majority population, height can affect productivity by a mechanism as straightforward as affecting the individual's ability to reach high shelves, to comfortably operate equipment, or to carry items that are large relative to height. Thus, finding a penalty to being shorter than average but no premium to being taller than average would suggest that below average height has a genuine productivity effect. The regressions reported in the tables include BMI as a single, continuous variable. The findings with respect to BMI are identical using alternative specifications allowing the effect of BMI to differ based on whether the individual is obese, overweight, or underweight, so the simplest specification is reported in the tables.

The wage regressions control for age and its square, where age is calculated from year of birth. ${ }^{29}$ As a measure of fluency in the English language, I use respondents' self-reports of how well they understand spoken English, where those reporting that they understand spoken English very well or well are assigned an indicator value of one. Potential alternative measures of English fluency are language of interview and interviewers' observations of fluency, but these have limitations as respondents had the option to choose the language of the interview, and even those self-reporting that they understand English very well often chose to be interviewed in another language. Interviewers only report language ability for those holding the interview in English.

Education is included in the wage regression, with total number of years of schooling completed separated into years of education in the United States and years outside the United States. As an alternative measure of education, I also consider whether there are degree effects, recording degrees attained in the United States and outside of the United States separately and recording bachelors, masters, JD, MD, and PhD degrees. In no instance is the coefficient on skin color affected other than trivially by the form in which education is measured, so the results reported in this article control for education in years.

I control for previous occupation before moving to the United States. Occupations are reported using 2003 census four-digit categories, which I group into five occupational categories: professional and managerial (codes 10-2960), health (codes 3000-3650), services (codes 3700-4650),

${ }^{29}$ Actual year of birth is missing for 739 observations but is reported as one of 10 categories spanning 5 years for $90 \%$ of the observations. For those with a missing year of birth but who have the age category reported, I calculate approximate age from the difference between interview year and the midpoint of the age category. 
sales and administrative (codes 4700-5930), and production (codes 60009750). The omitted category is those individuals not reporting an occupation in the source country.

An indicator variable for whether the respondent is a new-arrival immigrant is also included in the wage regressions. New-arrival immigrants acquired their immigration documents abroad, in contrast to "adjustee" immigrants who were already in the United States when they reached lawful permanent resident status. ${ }^{30} \mathrm{New}$ arrivals are likely to have lower wages than those who are more established in the United States. I also control for potential experience and its square, with potential labor market experience in the United States constructed as the difference between the interview date and the date of the first job in the United States. Because all sample members are new permanent legal residents, any previous work experience, if legal, would have occurred on a temporary work visa. There is no information on total actual work experience in the United States.

As discussed earlier, skin color discrimination may exist in the countries included in the sample. Thus, those with darker skin relative to others in their home country may end up with lesser amounts of unobservable human capital due to discrimination. Inclusion of information on family background should mitigate this potential omitted variables problem, as family background will control for economic opportunities growing up. I include in the wage equations father's education and relative family income at age 16 , reported in five categories ranging from childhood family income far below average to childhood family income far above average.

Regional variation in wages is taken into account by indicators for the census region to which the green card was sent, grouped into the four broad census categories of northeast, south, midwest, and west. Price changes over time are taken into account with an indicator for survey year as well as by the indicator for the NORC memo, sent about onefourth of the way through the survey field period to warn against overuse of the skin color rating of zero. The regressions also control for ethnicity, race, and country of birth in order to isolate the effect of skin color, height, and BMI from countrywide attributes correlated with these physical characteristics. I also report baseline estimates excluding ethnicity, race, and country of birth.

The remaining variables analyzed are potentially influenced by skin color discrimination in the United States and are added into the regressions in the second stage. These are variables relating to visa status and to

\footnotetext{
30 “Adjustees" include foreign students, temporary workers, refugees, or undocumented migrants who are adjusting from a nonimmigrant status to a legal immigrant status. Those already in the United States apply directly to the Bureau of Citizenship and Immigration Services (previously the Immigration and Naturalization Service) for permanent resident visas, while those not in the United States apply through the U.S. consular service in their home country.
} 
characteristics associated with current employment. I am not assuming that these variables are necessarily influenced by skin color discrimination but only that they may be. In fact, even region or whether the respondent is a new-arrival immigrant versus an adjustee could be endogenous. Immigrants with darker skin color may avoid certain U.S. regions because of concerns about discrimination, or there may be a difference in awarding permanent legal status on the basis of skin color between the Bureau of Citizenship and Immigration Services and the U.S. consular service in the respondent's home country. ${ }^{31}$

Respondents are categorized by type of visa, whether they are a spouse of a U.S. citizen, employment principal, diversity principal, or other, with other the omitted category in the regressions. The other category includes nonspousal family members of U.S. citizens and accompanying spouses of employment and diversity principals, as well as refugees and asylees and accompanying spouses and some who achieved their visa through legalization. Most employment visa holders are sponsored by their employer, raising the direct possibility that wage is endogenously determined with skin color for employment principals. ${ }^{32}$ Individuals eligible for diversity visas are from countries that have been underrepresented; they are required to have some education or work experience in an occupation requiring training, and, although selection is by lottery, eligibility for the lottery may also be influenced by skin color. Refugees and asylees may adjust from a temporary visa status to permanent residence after residing in the United States for 1 year. Those who obtain permanent resident status through legalization have met certain provisions after residing illegally in the United States.

Tenure is calculated from date of interview and month and year the respondent started the job. ${ }^{33}$ Occupations are reported using 2003 census four-digit codes, which I group into the same five occupational categories used for categorizing occupation before migrating to the United States, with production occupations the omitted category. I include indicators for whether the individual works for the government and for whether

${ }^{31}$ The possibility that skin color affects the decision of the United States to award permanent visas was suggested by a referee, and since visa applications require photos, this possibility cannot be ruled out. The referee suggested that applicants with dark skin who are admitted may have favorable characteristics that warrant a compensating wage differential. If so, then the estimated penalty to darker skin is underestimated relative to no such discrimination. There are no data available that would allow testing for discrimination in visa awards on the basis of skin color.

${ }^{32}$ Persons of extraordinary ability in sciences, arts, and so forth who will continue to work in their field can apply for a permanent visa on their own behalf rather than through an employer.

${ }^{33}$ Since actual start date is not reported, I calculate tenure assuming interview date and start date both occur on the fifteenth day of the month. 
the job is covered by a union contract. Government and union jobs in which wages are set for groups by pay grade or through negotiation would be less likely to show wage discrimination on the basis of skin color. However, access to such jobs or assignment to specific job categories may be affected by skin color, although an analysis of the probability that a worker is employed in a government or union job shows no relation to skin color.

Because outdoor work may cause skin color to darken, if jobs involving outdoor work are also lower paying, any estimated relation showing darker skin color and lower wages may be an artifact of the relation between outdoor work and lower wages. Note, however, that outdoor work may warrant higher wages as a compensating differential, which would serve to attenuate any negative effect of darker skin color on wages. There is no information on whether a respondent's job requires extensive work outdoors, and a direct measure of outdoor sun exposure is not available. As an alternative, I assign an indicator variable for occupations that are likely to require outdoor work. ${ }^{34}$

I define an indicator for those respondents who report their pay period as hourly, whether they also report that they are paid a salary or are selfemployed, as well as an indicator variable for full-time employment for those who report their usual hours per week as 35 hours or more. ${ }^{35}$ Those who report that their hours vary and do not report usual hours worked are classified as employed full time if they report their minimum hours worked per week as at least 35 hours. Those who do not report usual hours or minimum and maximum hours are excluded from the sample.

The wage regressions are based on the sample who are currently employed for pay, are working in the United States, have wages between $\$ 1.50$ and $\$ 100$ per hour, ${ }^{36}$ are not missing age (all respondents are age

${ }^{34}$ I identify such outdoor occupations if outdoor work is reported as a "highly probable" job characteristic in Kasper (2004), which is based on Occupational Information Network data. Occupations in which outdoor work is highly probable span a wide range and include petroleum engineer and environmental scientist in addition to the more obvious occupations in agriculture, construction, and grounds maintenance.

${ }^{35}$ Although any of these current labor market characteristics might potentially be endogenous, self-employment is of particular interest. An analysis shows that those with darker skin color are less likely to be self-employed, controlling for the same predetermined characteristics used in the regression equations reported below. While it might be tempting to interpret this finding as suggestive that immigrants with darker skin color avoid self-employment out of concern about customer discrimination, there is no information in the data regarding customer contact, and there is limited empirical evidence of customer discrimination in the literature generally, so it seems wisest to avoid making this leap.

${ }^{36}$ The wage equation results are the same if those with wages under $\$ 1.50$ or over $\$ 100$ are included in the estimates. 
18 or older), and have no more than 36 total years of education (only one respondent reports years of education in excess of 36 years, and only seven report education in excess of 26 years and are retained in the sample). The share with available wage data is quite high, with only $17 \%$ of those asked to report their regular pay failing to report earnings data. For comparison, Hirsch and Schumacher (2004) report that earnings are imputed for $30 \%$ of workers in the Current Population Survey because respondents refuse to answer or proxy respondents are unable to answer. Appendix B reports the effect of each restriction on the sample size. About $40 \%$ of the original sample is eliminated because the respondent is not working for pay or is self-employed but not asked to report pay, and another third of the remaining sample is eliminated because skin color is not available.

Inclusion of indicators for country as well as for race will largely account for skill differences that differ by country, as well as any intracountry effects of discrimination on the basis of race. For $29 \%$ of the sample described above, however, individual country is not identified in the public use data, and these observations are reported in the data set grouped into region. These region groups show somewhat greater racial variation than those identified by individual country (see table 1). Thus, unobserved intracountry heterogeneity across racial and ethnic groups within these broad regions may influence the relation between skin color and wage, although the direction of any possible bias is unclear a priori.

I thus analyze two samples, those in which individual country is reported in the public use data (1,536 observations) and those in which either individual country or region is reported (2,158 observations). Appendix $C$ reports sample means or percents for all variables used in the wage equation estimates for both samples (with the exception of country indicator variables).

\section{Regression Results}

Table 3 presents estimates from three specifications of the wage equation for the sample of 1,536 observations in which individual country is reported. These are the main results of interest in this article. The dependent variable in all equations is the log of hourly wage. The basic specification reported in column 1 controls for skin color, height, and BMI, as well as the other individual and pre-U.S. labor market characteristics not associated with current employment defined in Section V. The estimates in column 2 add to the basic specification of column 1 indicator variables for whether an individual is Hispanic and for race (reported in five mutually exclusive categories plus a category for multiple races and an indicator for race not reported, with white the omitted race category) and 
Table 3

Wage Equation Estimates for Sample with Individual Country Reported: Dependent Variable $=\ln$ (Hourly Wage)

\begin{tabular}{|c|c|c|c|c|c|c|}
\hline \multirow{3}{*}{ Skin color } & \multicolumn{2}{|c|}{ (1) } & \multicolumn{2}{|c|}{ (2) } & \multicolumn{2}{|l|}{ (3) } \\
\hline & $-.031 \% *$ & $(.006)$ & $-.017 * *$ & $(.007)$ & $-.011^{+}$ & $(.006)$ \\
\hline & & & & & & \\
\hline height & -.005 & $(.005)$ & -.006 & $(.005)$ & -.005 & $(.005)$ \\
\hline Inches above U.S. gender average & & & & & & \\
\hline height & $.019^{+}$ & $(.010)$ & $.020 \%$ & $(.010)$ & $.017^{+}$ & $(.009)$ \\
\hline Body mass index & -.003 & $(.002)$ & -.001 & $(.002)$ & -.000 & $(.002)$ \\
\hline Male & $.214 * *$ & $(.025)$ & $.213 * *$ & $(.024)$ & $.174 \%$ & $(.024)$ \\
\hline Age & $.032 * *$ & $(.008)$ & $.029 *$ & $(.008)$ & $.019 * *$ & $(.007)$ \\
\hline $\mathrm{Age}^{2} / 100$ & $-.041 * *$ & $(.009)$ & $-.038 * *$ & $(.009)$ & $-.028 * *$ & $(.009)$ \\
\hline $\begin{array}{l}\text { Understand English very well/ } \\
\text { well }\end{array}$ & $.159 \% *$ & $(.028)$ & $.115 \% *$ & $(.029)$ & $087 \% *$ & $(.027)$ \\
\hline Education in United States & $.020 * *$ & $(.006)$ & $.022 * *$ & $(.006)$ & $.012 \%$ & $(.005)$ \\
\hline Education outside United States & $.027 * *$ & $(.003)$ & $.023 * *$ & $(.003)$ & $.013 * *$ & $(.003)$ \\
\hline $\begin{array}{l}\text { Professional, managerial occupa- } \\
\text { tion before United States }\end{array}$ & $.120 \% *$ & $(.036)$ & $.099 * *$ & $(.036)$ & .036 & $(.033)$ \\
\hline Health occupation before United & & & & & & \\
\hline States & $.301 * *$ & $(.066)$ & $.234 * *$ & $(.065)$ & $.180 * *$ & $(.062)$ \\
\hline Service occupation before United & & & & & & \\
\hline States & -.028 & $(.052)$ & -.052 & $(.051)$ & -.032 & $(.047)$ \\
\hline $\begin{array}{l}\text { Sales and administrative occupa- } \\
\text { tion before United States }\end{array}$ & -.056 & $(.037)$ & -.052 & $(.036)$ & .002 & $(.033)$ \\
\hline Production occupation before & & & & & & \\
\hline United States & -.034 & $(.033)$ & -.023 & $(.033)$ & -.033 & $(.030)$ \\
\hline New arrival & $-.174 * *$ & $(.033)$ & $-.172 * *$ & $(.034)$ & $-.129 * *$ & $(.033)$ \\
\hline Potential U.S. work experience & $.031 \% *$ & $(.005)$ & $.030 * \div$ & $(.005)$ & $.016 \%$ & $(.005)$ \\
\hline Potential U.S. work & & & & & & \\
\hline experience ${ }^{2} / 100$ & $-.076 * *$ & $(.021)$ & $-.065^{* *}$ & $(.021)$ & -.030 & $(.020)$ \\
\hline Father's years of education & $.007 * *$ & $(.003)$ & .004 & $(.003)$ & .001 & $(.003)$ \\
\hline Childhood family income far be- & & & & & & \\
\hline low average & -.026 & $(.037)$ & -.016 & $(.036)$ & -.019 & $(.033)$ \\
\hline Childhood family income below & & & & & & \\
\hline average & $-.089 *$ & $(.031)$ & $-.071 \%$ & $(.030)$ & $-.085 * *$ & $(.027)$ \\
\hline $\begin{array}{l}\text { Childhood family income above } \\
\text { average }\end{array}$ & .003 & & .001 & & & \\
\hline Childhood family income far & & & & & & ) \\
\hline above average & -.056 & $(.065)$ & -.045 & $(.063)$ & -.046 & $(.058)$ \\
\hline Northeast & -.019 & $(.039)$ & -.023 & $(.044)$ & -.009 & $(.040)$ \\
\hline Midwest & -.044 & $(.042)$ & $-.091^{+}$ & $(.048)$ & -.056 & $(.044)$ \\
\hline West & -.029 & $(.037)$ & $-.079^{+}$ & $(.043)$ & -.012 & $(.040)$ \\
\hline Skin color reminder memo & .036 & $(.028)$ & $.050^{+}$ & $(.028)$ & $.043^{+}$ & $(.025)$ \\
\hline Year 2004 & .034 & $(.031)$ & .032 & $(.030)$ & .024 & $(.027)$ \\
\hline Spouse of U.S. citizen & & & & & -.042 & $(.026)$ \\
\hline Employment visa & & & & & $.418 * *$ & $(.047)$ \\
\hline Diversity visa & & & & & .029 & $(.068)$ \\
\hline Tenure & & & & & $.024 * *$ & $(.006)$ \\
\hline Tenure $^{2} / 100$ & & & & & $-.080 *$ & $(.036)$ \\
\hline Professional, managerial & & & & & & \\
\hline & & & & & $.309 * *$ & $(.045)$ \\
\hline Health occupation & & & & & $.103 \%$ & $(.048)$ \\
\hline Service occupation & & & & & $-.165 \%$ & $(.027)$ \\
\hline Sales and administrative & & & & & & \\
\hline occupation & & & & & -.049 & $(.033)$ \\
\hline Government employer & & & & & .030 & $(.054)$ \\
\hline Union contract & & & & & $.059 \%$ & $(.029)$ \\
\hline Outdoor work highly probable & & & & & $.139 *$ & $(.056)$ \\
\hline
\end{tabular}


Table 3 (Continued)

\begin{tabular}{|c|c|c|c|c|c|}
\hline \multirow[b]{2}{*}{ Paid hourly rate } & \multirow[t]{2}{*}{ (1) } & \multicolumn{2}{|c|}{ (2) } & \multicolumn{2}{|c|}{ (3) } \\
\hline & & & & -.024 & $(.029)$ \\
\hline Full time & & & & .014 & $(.028)$ \\
\hline Self-employed & & & & -.004 & $(.052)$ \\
\hline Hispanic/Latino & & -.089 & $(.077)$ & -.073 & $(.070)$ \\
\hline American Indian/Alaska native & & -.050 & $(.059)$ & -.025 & $(.053)$ \\
\hline Asian & & -.018 & $(.135)$ & -.011 & $(.122)$ \\
\hline Black & & -.137 & $(.123)$ & -.072 & $(.113)$ \\
\hline \multicolumn{6}{|l|}{ Native Hawaiian/other Pacific } \\
\hline Islander & & .169 & $(.164)$ & .148 & $(.148)$ \\
\hline Multiple races & & .130 & $(.114)$ & $.197^{+}$ & $(.103)$ \\
\hline Race not reported & & -.005 & $(.039)$ & .004 & $(.036)$ \\
\hline Constant & $1.264 * *(.161)$ & $1.403 * *$ & $(.174)$ & $1.685 \%$ & $(.167)$ \\
\hline Adjusted $R^{2}$ & .33 & .38 & & .49 & \\
\hline Country indicators & No & Yes & & Yes & \\
\hline
\end{tabular}

Note. - Number of observations $=1,536$. Standard errors are in parentheses. See text and app. B for composition of sample. All values weighted to account for sample design and response rates. Indicator variables for missing values for height, body mass index, father's education, childhood family income, and tenure are included in the equations, but these coefficients are not reported. Indicator variables for country are included in the equations reported in cols. 2 and 3, but these coefficients are not reported.

$+p<.10$.

$* p<.05$.

$* \% p<.01$.

for country of birth. Column 3 adds information on current labor market characteristics to the specification of column 2.

Before turning to the wage equation results, it is worth examining two specification issues. First, since skin color information is not available for nearly half of the sample that has wage information and as that half is therefore not included in the wage regressions reported in this article, I examine whether there is a structural difference in the wage equations based on whether skin color is reported. Second, I examine whether it is appropriate to pool males and females in the sample, allowing only an intercept difference by gender. Although it is well known that much of the gender difference in returns to characteristics in wage equations is reflected in the intercept (e.g., see Altonji and Blank 1999), it is worthwhile to consider whether controlling for sex using only an intercept would be appropriate for the questions of interest in this article.

Regarding the first issue, there is little evidence that there is a structural difference in the wage equation based on whether skin color is reported. Tests of the null hypothesis that all coefficients are equal based on the specifications reported in columns $1-3$ yield $F$-values of $2.06,1.58$, and 1.61. Although the corresponding $p$-values are under .01 , the differences in the coefficients are small, and there does not appear to be any systematic bias that would limit the generality of the results to all new lawful immigrants. This combined with the finding that the results are virtually identical when using weights adjusted for whether skin color is reported (see n. 16) suggests that the results can be generalized to all immigrants 
and that systematic bias arising from lack of skin color data is not a problem.

Second, there also is little evidence of structural differences by gender in the wage equation beyond an intercept difference. Tests of the null hypothesis that all coefficients but the intercept are equal in the male and female equations corresponding to the specifications reported in table 3 yields $F$-values (and corresponding $p$-values) of $1.22(p$-value $=.19), 1.85$ $(p$-value $<.01)$, and $1.40(p$-value $=.02)$. Although two of these three $F$ tests suggest structural differences by sex at the $5 \%$ level, the differences by sex in individual coefficients are minor and are rarely statistically significant. Furthermore, in no specification can the hypothesis be rejected that the coefficients on skin color, height, and BMI in the male and female equation are equal, either individually or jointly. Alternative specifications allowing the effect of BMI to differ based on whether the respondent is obese, overweight, or underweight likewise show neither a significant effect of BMI nor structural differences by sex. Given the limited evidence of structural differences by sex, all regressions pool male and female respondents and include an indicator variable for sex.

Turning to the results reported in table 3, of particular interest are the effects of skin color, height, and BMI on wages. There is a wage advantage of about $2 \%$ with every additional inch of height over the U.S. genderspecific average, significant at the $10 \%$ level in all specifications. There is no penalty to being shorter than the U.S. gender average. BMI has no effect on wages in any specification.

The magnitude of the skin color penalty is largest when ethnicity, race, and country of birth are excluded, as indicated in table 3 , column 1 . Column 2 includes indicators for ethnicity, race, and country of birth in addition to the pre-U.S. labor market characteristics. Inclusion of these indicators reflects at least in part the influence of unobserved characteristics that may be correlated with skin color. Unsurprisingly, the addition of indicators for ethnicity, race, and country of birth results in a decrease in the coefficient on skin color, as these factors are highly correlated with skin color. The skin color coefficient in column 2 is about half the size of that reported in column 1 .

Table 3, column 2, shows that an additional unit of skin color darkness on the 11-point scale lowers wage by $1.7 \%$, significant at the $1 \%$ level. A 1-standard-deviation increase in skin color darkness lowers wages by $3.4 \%$. The 10th-90th percentile range for the skin color distribution is four points on the 11-point scale for immigrants from majority Asian countries and is five points for immigrants from majority Hispanic, black, or white countries. Thus, on average, moving from the 10th percentile to the 90 th percentile on the skin color scale would reduce wages by $6.8 \%-8.5 \%$ based on the results presented in column 2 .

Table 3, column 3, adds current labor market characteristics to the es- 
timates reported in column 2. Notably, even when controlling for current labor market characteristics that may themselves be subject to skin color discrimination, darker skin color continues to have a negative effect on wage. The magnitude of the effect drops to $1.1 \%$, with a $p$-value of .06 .

The other variables reported in table 3 are also of interest. Unsurprisingly, inclusion of current labor market characteristics in column 3 results in lower returns to pre-U.S. labor market characteristics, but the general patterns are the same across the three specifications. The returns to being male, to age, and to work experience show the conventional patterns observed throughout the literature. Wages are $9 \%-17 \%$ higher for those with proficiency in the English language. Wages increase with years of education, regardless of whether acquired in the United States or in the country of birth. Notably, the magnitudes of the returns to education acquired in the United States and in the country of birth are very similar, and the hypotheses that they are the same cannot be rejected. ${ }^{37} \mathrm{New}$ arrivals have wages about $14 \%-19 \%$ lower than those who were living in the United States when they achieved lawful permanent resident status. Father's education is associated with higher wages only in the specification reported in column 1, and those with childhood family income below average have lower wages. As indicated in columns 2 and 3, wages do not differ on the basis of Hispanic ethnicity and race relative to the omitted category of white immigrants. This finding is driven by the inclusion of country indicators in the regressions, not the inclusion of skin color, as results excluding skin color from the equations show the same pattern with respect to ethnicity and race. ${ }^{38}$

The results in column 3 of table 3 that add visa type and current labor market characteristics show that those with employment visas earn considerably more than those with other visa types, with a premium of about $52 \%$. Those with employment visas are largely concentrated in the professional and health occupations. Specifically, $70 \%$ of those with em-

${ }^{37}$ Using data on immigrants to Israel, Friedberg (2000) finds the return to experience differs by whether the experience was acquired in the originating country or in Israel, with a much higher return to experience acquired in Israel. The similarity of the returns to education regardless of where acquired suggests that education is more portable than work experience. Chiswick and Miller (2007) examine the determinants of overeducation and undereducation among native and foreign-born men. They find more mismatches among foreign-born men than among native-born men, with foreign-born men with greater preimmigration work experience more likely to be in poor matches. Their findings suggest that preimmigration skills are not perfectly transferable. A possible implication is that the returns to education acquired in the source country would be lower than the returns to education acquired in the United States.

${ }^{38}$ Adding skin color to a specification that already includes race and country indicators slightly raises the adjusted $R^{2}$, as would be expected by the size of the coefficient on skin color relative to the standard error. 
ployment visas are in professional or health occupations, in contrast to $19 \%$ of those with spouse visas and $12 \%$ of those with diversity or other visas. Wages increase with tenure at a decreasing rate and are higher for occupations for which outdoor work is highly probable, indicative of a compensating differential for outdoor work. ${ }^{39}$ Workers in professional and health occupations have higher wages relative to those in production occupations, while those in service occupations have lower wages. The union premium is $6 \%$.

Table 4 reports the counterpart of table 3 , based on the 2,158 observations with either individual country or region reported. The results are quite similar to those reported in table 3 . The role of intracountry heterogeneity is indicated by the smaller coefficients on skin color than in the estimates reported in table 3. The coefficient on skin color ranges from -0.021 ( $p$-value $<.01$ ), in the estimates controlling for pre-U.S. labor market characteristics and excluding ethnicity, race, and country of birth reported in column 1 , to -0.008 ( $p$-value $=.11)$, in the estimates controlling for pre-U.S. labor market and current labor market characteristics as well as ethnicity, race, and country of birth reported in column 3 .

Because skin color and race are so highly correlated and because considerable evidence shows that blacks earn less than whites in the United States, it is worthwhile considering whether the inverse relation between darker skin color and wages arises from the lower wages paid to blacks generally. Exclusion of blacks from the sample shows this is not the case. The skin color coefficients and standard errors that correspond to the results reported in table 3 are $-0.023(0.007)$ for column $1,-0.016(0.007)$ for column 2 , and $-0.012(0.006)$ for column 3 . The results corresponding to table 4 but excluding blacks are also close to the results reported in table $4 .^{40}$

\footnotetext{
${ }^{39}$ Because the survey was administered over an entire year, skin color may vary because of exposure to sun. To the extent that immigrants participate in intentional tanning, and assuming that wages do not adjust instantaneously to variations in skin color caused by tanning, interviewers would report a darker color for individuals who are actually lighter colored, thus biasing downward the wage penalty associated with darker skin color. Unintentional tanning that may be associated with outdoor work is accounted for by the indicator for outdoor work, whose coefficient shows a positive wage effect of outdoor work. I also estimated wage equations, controlling for survey quarter to approximate sun exposure over the year. The skin color effect is unaffected.

${ }^{40}$ Also of interest is whether the effect of skin color differs by ethnicity or race. To conduct this test, I create a category for Hispanic ethnicity that is disjoint from the mutually exclusive race categories and include the interactions of skin color with Hispanic ethnicity and Asian, black, and white. Tests of the hypothesis that the effect of skin color does not differ by Hispanic ethnicity or race cannot be rejected, with $F$-statistics of $1.12(p$-value $=.34)$ for the specification corresponding to table 3 , col. 2 , and $0.96(p$-value $=.41)$ for the specification corresponding to table 4 , col. 2 .
} 
As discussed earlier, skin color discrimination may exist in the countries included in the sample. Most of the effect of any skin color discrimination in the source country is likely to be reflected in the observable characteristics included in the wage regressions, particularly education and occupation before migrating to the United States. But it is possible that those with darker skin relative to those in their home country may end up with lesser amounts of unobservable human capital due to discrimination. The equations include information on family background, which should mitigate this potential omitted variables problem, as family background will control for economic opportunities growing up. Although the results in tables 3 and 4 provide some evidence that family background affects wages, the magnitude of the effects are fairly minor. Exclusion of family background variables yields coefficients on skin color identical to those reported in columns 2 and 3 of tables 3 and 4, with only a slight difference in the coefficients on skin color in column 1 of tables 3 and 4. However, if only demographic and family background characteristics are included in the wage equations, father's education and relative family income show a more consistent and stronger relation with wages. This suggests that family background is correlated with observable outcomes such as education and occupation, and inclusion of these outcomes largely accounts for the role of family background in determining wages. A similar reasoning would apply to unobserved ability. Thus, it seems possible that any other unmeasured characteristics associated with skin color will likewise largely be captured by measured characteristics that are included in the wage equations. ${ }^{41}$

\section{Conclusion}

This article finds that new lawful immigrants to the United States with lighter skin color have higher wages relative to their counterparts with darker skin color. Height above the U.S. average also has a positive effect on wages of immigrants. While height may reflect greater amounts of health capital and thereby have a direct positive effect on wages, it is less likely that skin color reflects any attribute related to productivity.

Discrimination on the basis of skin color is a possible explanation of the skin color effect on wages. Inferring discrimination from wage equations is a residual hypothesis, so it is necessary to examine whether the

\footnotetext{
${ }^{41}$ As a second test of whether unobserved characteristics associated with skin color discrimination at home may be the source of the observed skin color effect, I calculated a standardized deviation from country of birth average skin color using data on all respondents with skin color reported whether employed or not. Inclusion of this variable in the wage equation indicates that those with darker skin color relative to the average in their country of birth actually had slightly higher, not lower, wages. The wage equation estimates continue to show a negative effect of darker skin color on wages.
} 
Table 4

Wage Equation Estimates for Sample with Individual Country or

Region Reported: Dependent Variable $=\ln$ (Hourly Wage)

\begin{tabular}{|c|c|c|c|c|c|c|}
\hline \multirow[b]{2}{*}{ Skin color } & \multicolumn{2}{|c|}{ (1) } & \multicolumn{2}{|c|}{ (2) } & \multicolumn{2}{|c|}{ (3) } \\
\hline & $-.021 \% *$ & $(.005)$ & $-.012 *$ & $(.006)$ & -.008 & $(.005)$ \\
\hline Inches below U.S. gender average & & & & & & \\
\hline $\begin{array}{l}\text { height } \\
\text { Inches above U.S. gender average }\end{array}$ & -.006 & $(.004)$ & -.007 & $(.004)$ & -.005 & $(.004)$ \\
\hline height & $.020 \% *$ & $(.008)$ & $.019 *$ & $(.008)$ & $.017 *$ & $(.007)$ \\
\hline Body mass index & -.002 & $(.002)$ & -.000 & $(.002)$ & .000 & $(.002)$ \\
\hline Male & $.179 * *$ & $(.021)$ & $.180 \% *$ & $(.021)$ & $.134 \% *$ & $(.020)$ \\
\hline Age & $.037 \% *$ & $(.007)$ & $.034 * *$ & $(.007)$ & $.025 \%$ & $(.006)$ \\
\hline $\mathrm{Age}^{2} / 100$ & $-.046 \% *$ & $(.008)$ & $-.044 * *$ & $(.008)$ & $-.035 \% *$ & $(.008)$ \\
\hline $\begin{array}{l}\text { Understand English very well/ } \\
\text { well }\end{array}$ & $.159 \% \%$ & $(.024)$ & $.118 * *$ & $(.02$ & $.087 \% *$ & $(.02$ \\
\hline Education in United States & $.019 * *$ & $(.005)$ & $.021 * *$ & $(.005)$ & $.009 *$ & $(.004)$ \\
\hline Education outside United States & $.024 \% *$ & $(.003)$ & $.021 \% *$ & $(.003)$ & $.011 \% *$ & $(.003)$ \\
\hline $\begin{array}{l}\text { Professional, managerial occupa- } \\
\text { tion before United States } \\
\text { Health occupation before United }\end{array}$ & $.093 \%$ & $(.030)$ & $.074 *$ & $(.030)$ & .020 & $(.027)$ \\
\hline $\begin{array}{l}\text { States } \\
\text { Service }\end{array}$ & $.258 * \%$ & $(.058)$ & $.204 \% *$ & $(.057)$ & $.168 * \%$ & $(.054)$ \\
\hline States & -.005 & $(.044)$ & -.020 & $(.043)$ & -.013 & $(.039)$ \\
\hline $\begin{array}{l}\text { Sales and administrative occupa- } \\
\text { tion before United States } \\
\text { Production occupation before }\end{array}$ & $-.060 *$ & $(.030)$ & $-.060 *$ & $(.030)$ & -.021 & $(.027)$ \\
\hline Unite & -.019 & $(.030)$ & -.013 & $(.030)$ & -.027 & $(.027)$ \\
\hline $\mathrm{New}$ ar & $-.196 \% *$ & $(.028)$ & $-.197 * *$ & $(.028)$ & $-.142 * *$ & $(.028)$ \\
\hline Potential U.S. work ex & $.033 * *$ & $(.005)$ & $.033 *$ & $(.005)$ & $.017 * *$ & $(.004)$ \\
\hline $\begin{array}{l}\text { Potential U.S. work } \\
\text { experience } 2 / 100\end{array}$ & $-.085 * *$ & $(.01$ & $.077 \% *$ & $(.019)$ & $-.035^{+}$ & \\
\hline Father's years of education & $.010 * *$ & $(.002)$ & $.008 *$ & $(.002)$ & $.004 *$ & $(.002)$ \\
\hline $\begin{array}{l}\text { Childhood family income far be- } \\
\text { low average }\end{array}$ & -.029 & $(.034)$ & -.015 & $(.034)$ & -.014 & $(.030)$ \\
\hline Childhood family income below & $-.058 \%$ & $(.026)$ & $-.053 *$ & $(.026)$ & $-.067 * *$ & $(.024)$ \\
\hline $\begin{array}{l}\text { Childhood family income above } \\
\text { average }\end{array}$ & .014 & $(.031)$ & .019 & $(.031)$ & .001 & $(.028)$ \\
\hline $\begin{array}{l}\text { Childhood family income far } \\
\text { above average }\end{array}$ & -.046 & $(.05$ & -.034 & & -.021 & $(.050)$ \\
\hline Northeast & .015 & $(.03$ & .015 & & .020 & $(.031)$ \\
\hline Midwe & -.014 & $(.035)$ & -.049 & $(.038)$ & -.031 & $(.035)$ \\
\hline West & -.011 & $(.031)$ & -.047 & $(.034)$ & .012 & $(.031)$ \\
\hline Skin color reminder & $.042^{+}$ & $(.025)$ & $.054 \%$ & $(.024)$ & $.051 \%$ & $(.022)$ \\
\hline Year 2004 & -.007 & $(.026)$ & -.003 & $(.026)$ & .002 & $(.023)$ \\
\hline Spouse of U.S. & & & & & -.018 & $(.022)$ \\
\hline Emplo & & & & & $.399 \% *$ & $(.040)$ \\
\hline Divers & & & & & -.037 & $(.044)$ \\
\hline Tenur & & & & & $.020 \% *$ & $(.006)$ \\
\hline Tenure & & & & & $-.071 *$ & $(.03$ \\
\hline $\begin{array}{l}\text { Professional, managerial } \\
\text { occupation }\end{array}$ & & & & & $.317 \% *$ & \\
\hline Healt & & & & & $.103 *$ & $(.041)$ \\
\hline Service occupation & & & & & $-.168 \% \%$ & $(.024)$ \\
\hline $\begin{array}{l}\text { Sales and administrative } \\
\text { occupation }\end{array}$ & & & & & $-.061 \%$ & $(027)$ \\
\hline employer & & & & & -.025 & $(.046)$ \\
\hline & & & & & $.045^{+}$ & $(.027)$ \\
\hline Outdoor work highly probable & & & & & $.153 \% *$ & $(.051)$ \\
\hline
\end{tabular}


Table 4 (Continued)

\begin{tabular}{|c|c|c|c|c|c|}
\hline \multirow[b]{2}{*}{ Paid hourly rate } & \multirow[t]{2}{*}{ (1) } & \multicolumn{2}{|c|}{ (2) } & \multicolumn{2}{|c|}{ (3) } \\
\hline & & & & -.029 & $(.023)$ \\
\hline Full time & & & & .008 & $(.024)$ \\
\hline Self-employed & & & & -.042 & $(.044)$ \\
\hline Hispanic/Latino & & -.036 & $(.056)$ & .008 & $(.051)$ \\
\hline American Indian/Alaska native & & -.032 & $(.055)$ & .000 & $(.050)$ \\
\hline Asian & & -.062 & $(.076)$ & -.019 & $(.069)$ \\
\hline Black & & -.010 & $(.068)$ & .034 & $(.061)$ \\
\hline \multicolumn{6}{|l|}{ Native Hawaiian/other Pacific } \\
\hline Islander & & .137 & $(.101)$ & .113 & $(.091)$ \\
\hline Multiple races & & .148 & $(.114)$ & $.199^{+}$ & $(.103)$ \\
\hline Race not reported & & .006 & $(.037)$ & .020 & $(.033)$ \\
\hline Constant & $1.085 *(.139)$ & $1.159 *$ & $(.150)$ & $1.455 * *$ & $(.143)$ \\
\hline Adjusted $R^{2}$ & .31 & .35 & & .47 & \\
\hline Country or region indicators & No & Yes & & Yes & \\
\hline
\end{tabular}

Note. - Number of observations $=2,158$. Standard errors are in parentheses. See text and app. B for composition of sample. All values weighted to account for sample design and response rates. Indicator variables for missing values for height, body mass index, father's education, childhood family income, and tenure are included in the equations, but these coefficients are not reported. Indicator variables for country or region are included in the equations reported in cols. 2 and 3 , but these coefficients are not reported.

$+p<.10$.

$* p<.05$.

$* \% p<.01$.

skin color effects may be driven by omitted productivity characteristics correlated with skin color. All wage equations reported in this article control for a wide array of characteristics determined prior to current U.S. employment, including education, family background, and occupation in the source country. The magnitude of the skin color effect is lower when current labor market characteristics are included in the wage equations, indicating that these additional current labor market variables are correlated with skin color and explain part of the skin color effect that appears when controlling only for pre-U.S. labor market characteristics. However, current labor market variables may also be influenced by the same possible discriminatory process under examination.

Because inclusion of additional observables reduces the magnitude of the estimated skin color effect, it is worthwhile to consider what might be missing from the wage equations. Two possible omitted variables are attractiveness and some measure of ability as embodied in test scores.

Studies show that attractiveness is associated with superior economic outcomes (e.g., Hamermesh and Biddle 1994). Hersch (2006) reports data showing that interviewers were far more likely to rate African Americans with lighter skin as more attractive than average. However, inclusion of attractiveness in a wage equation did not alter the estimated effect of skin color on wages. While it remains possible that the effect of skin color among immigrants may arise via a link with attractiveness, Hersch's (2006) results suggest that any such effect is not likely to be large enough to explain the substantial skin color effects observed here. 
The possible connection between skin color and ability has been examined using the 1982 GSS, which includes a 10-item vocabulary test as well as a measure of skin color for a sample of about 500 African Americans. Using these data, Lynn (2002) reports a positive correlation between lighter skin color and higher test scores. However, using the same data, Hill (2002) demonstrates that controlling for education and family background eliminates the relation between skin color and test scores. This 10 -item vocabulary test is likely to have more measurement error than a test such as the Armed Forces Qualification Test, possibly biasing the estimated effect of skin color on test score toward zero, but it is the only available test that can be used to examine a skin color-test score relation. Available evidence in the scientific literature does not support a link between skin color and intelligence. ${ }^{42}$ In addition, the correlation between skin color and ancestry varies considerably, with low correlations in many populations of mixed ancestry (Parra, Kittles, and Shriver 2004). In the absence of genetic evidence or a high correlation between skin color and ancestry, it seems unlikely that inclusion of test scores as a measure of ability would greatly alter the skin color effects found in this article.

Other omitted variables could be posited, and it is worthwhile to examine what conditions need to met for the observed skin color effect to be explained by an omitted variable. First, any omitted variable would need to be correlated with both skin color and market productivity. The correlation would require that those with more of this omitted variable are more productive and also have lighter skin color. If instead those with more of this characteristic have darker skin color, the estimates presented in this article understate the skin color wage gap. Second, as the wage equations control for a wide array of characteristics, the omitted variable would need to have a low correlation with the non-skin-color variables already included in the analysis in order to have a substantial impact on the magnitude of the skin color effect.

Thus, discrimination against immigrants with darker skin relative to those with lighter skin remains a possible explanation for the findings of this article. The results indicate that any such discrimination is not merely ethnic or racially based nor due to country of birth. Wage equations controlling for ethnicity, race, and country of birth, as well as for family background and extensive labor market characteristics, including characteristics that may themselves be affected by skin color discrimination, show that gradations of skin color affect wages. Skin color is not merely capturing the effects of ethnicity, race, or country of birth but also has an independent effect on wages.

${ }^{42}$ In November 2004, Nature Genetics (suppl. vol. 36, no. 11) devoted an issue to race and the genome. 


\section{Appendix A}

\section{Skin Color Scale}

The NIS measured respondent skin color using a scale designed by Douglas S. Massey (one of the principal investigators) and Jennifer A. Martin (NIS project manager), based on an idea originally developed by Massey et al. (2003) in their work on the National Longitudinal Study of Freshmen. The scale is an 11-point scale, ranging from zero to 10, with zero representing albinism, or the total absence of color, and 10 representing the darkest possible skin. The 10 shades of skin color corresponding to points one to 10 on the Massey and Martin Skin Color Scale are depicted in a chart, with each point represented by a hand, of identical form but differing in color. The scale was constructed with assistance from a graphic designer. The Massey and Martin Scale is for use by interviewers, who essentially memorize the scale, so that the respondent never sees the chart. A facsimile of the NIS Skin Color Scale appears in figure A1.

\section{Scale of Skin Color Darkness}

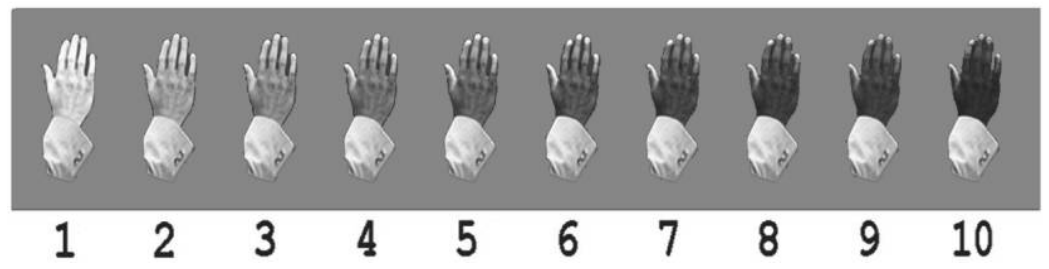

FIg. A1.-NIS Skin Color Scale. Source: Massey and Martin (2003). Color version available as an online enhancement.

The Martin and Massey NIS Skin Color Scale was first printed in an appendix to the Field Interviewer Manual during the baseline round of the NIS. The manual included the following instruction:

As you know, human beings display a wide variety of physical attributes. One of these is skin color. Unfortunately discrimination on the basis of skin color continues to be a reality in American life. Substantial evidence suggests that lighter skinned people fare better in a variety of social and economic settings than those with darker skins. In order to detect such discrimination, it is important that the NIS include a measure of skin color. We therefore ask interviewers to use the Scale of Skin Color Darkness as a guide to rate the skin color of each respondent on a scale of 0 to 10 , where 0 is the lightest possible skin color (such as that of an albino) and 10 is the darkest possible skin color. Please rate the skin color of ALL respondents upon the completion of the interview, be they of European, Asian, Latin American, or African origin. It is very important that we obtain this information for everyone, not just those of obvious African ancestry.

It is important that you become familiar with the scale so that you do 
not access it during the interview. Respondents should never see the scale. (Massey and Martin 2003, 1)

Users of the NIS Skin Color Scale are requested to kindly notify the NIS Project staff by e-mailing the project manager, Jennifer A. Martin(nis@opr .princeton.edu).

\section{Appendix B}

Table B1

Construction of Sample

\begin{tabular}{lcc}
\hline & $\begin{array}{c}\text { Net Number } \\
\text { Affected }\end{array}$ & $\begin{array}{c}\text { Number } \\
\text { Remaining }\end{array}$ \\
\hline Initial sample & & 8,573 \\
Overseas immigrant & 321 & 8,252 \\
Not working for pay & 3,319 & 4,933 \\
Not working in United States & 71 & 4,862 \\
Missing country of birth & 10 & 4,852 \\
Self-employed and not paid regular salary or wage & 152 & 4,700 \\
Missing age & 24 & 4,676 \\
Missing education & 13 & 4,663 \\
Missing wage & 809 & 3,854 \\
Hourly wage $<$ \$1.50 or $>$ \$100 & 33 & 3,821 \\
Missing whether employed full time & 6 & 3,815 \\
Missing skin color & 1,657 & 2,158 \\
Individual country not reported in public use data & 622 & 1,536 \\
\hline
\end{tabular}

SOURCE.-New Immigrant Survey 2003.

\section{Appendix C}

Table C1

Descriptive Statistics for Samples Used in Wage Regressions

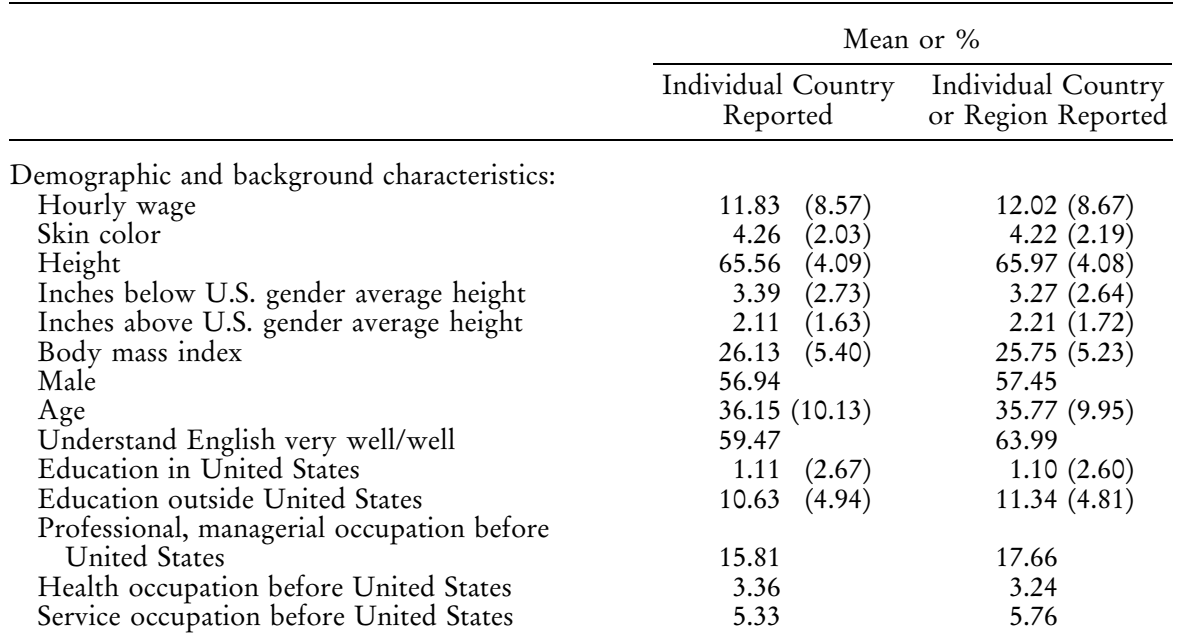


Table C1 (Continued)

\begin{tabular}{|c|c|c|}
\hline & \multicolumn{2}{|c|}{ Mean or $\%$} \\
\hline & $\begin{array}{l}\text { Individual Country } \\
\text { Reported }\end{array}$ & $\begin{array}{l}\text { Individual Country } \\
\text { or Region Reported }\end{array}$ \\
\hline \multicolumn{3}{|l|}{ Sales and administrative occupation before } \\
\hline United States & 13.55 & 15.32 \\
\hline Production occupation before United States & 18.60 & 17.21 \\
\hline New arrival & 24.51 & 26.30 \\
\hline Potential U.S. work experience & $6.33(6.75)$ & $5.68(6.36)$ \\
\hline \multicolumn{3}{|l|}{ Family background: } \\
\hline Father's years of education & $7.72(5.97)$ & $8.66(6.03)$ \\
\hline Childhood family income far below average & 13.93 & 11.70 \\
\hline Childhood family income below average & 19.90 & 19.60 \\
\hline Childhood family income average & 49.77 & 51.76 \\
\hline Childhood family income above average & 12.37 & 13.14 \\
\hline Childhood family income far above average & 3.28 & 3.25 \\
\hline \multicolumn{3}{|l|}{ Visa status and current labor status characteristics: } \\
\hline Spouse of U.S. citizen & 34.25 & 37.10 \\
\hline Employment visa & 6.84 & 6.99 \\
\hline Diversity visa & 3.30 & 5.62 \\
\hline Other visa & 55.60 & 50.29 \\
\hline Tenure & $2.80(4.17)$ & $2.45(3.83)$ \\
\hline Professional, managerial occupation & 11.28 & 13.89 \\
\hline Health occupation & 7.42 & 7.38 \\
\hline Service occupation & 26.25 & 25.43 \\
\hline Sales and administrative occupation & 17.43 & 19.45 \\
\hline Production occupation & 37.34 & 33.65 \\
\hline Government employer & 3.91 & 4.16 \\
\hline Union contract & 14.49 & 12.90 \\
\hline Outdoor work highly probable & 3.41 & 3.04 \\
\hline Paid hourly rate & 72.17 & 70.47 \\
\hline Full time & 82.13 & 81.32 \\
\hline Self-employed & 4.94 & 4.76 \\
\hline \multicolumn{3}{|l|}{ Location where green card sent: } \\
\hline Northeast & 24.55 & 27.49 \\
\hline Midwest & 16.65 & 17.01 \\
\hline West & 45.60 & 41.32 \\
\hline South & 13.20 & 14.18 \\
\hline \multicolumn{3}{|l|}{ Ethnicity and race: } \\
\hline Hispanic/Latino & 60.54 & 49.95 \\
\hline American Indian/Alaska native & 3.86 & 3.29 \\
\hline Asian & 18.53 & 18.71 \\
\hline Black & 7.58 & 10.20 \\
\hline Native Hawaiian/other Pacific Islander & .59 & 1.19 \\
\hline White & 58.49 & 57.53 \\
\hline Multiple races & 1.05 & .76 \\
\hline Race not reported & 9.90 & 8.32 \\
\hline \multicolumn{3}{|l|}{ Percent with missing values: } \\
\hline Height & 3.86 & 3.18 \\
\hline Body mass index & 4.54 & 4.04 \\
\hline Father's education & 25.24 & 25.50 \\
\hline Childhood family income & .75 & .54 \\
\hline Tenure & .61 & .71 \\
\hline Number of observations & 1,536 & 2,158 \\
\hline
\end{tabular}




\section{References}

Altonji, Joseph G., and Rebecca M. Blank. 1999. Race and gender in the labor market. In Handbook of labor economics, vol. 3, ed. Orley Ashenfelter and David Card. Amsterdam: Elsevier Science.

Becker, Gary S. 1957/1971. The economics of discrimination. Chicago: University of Chicago Press.

Bernard, William S. 1980. Immigration: History of U.S. policy. In Harvard encyclopedia of American ethnic groups, ed. Stephan Thernstrom, Ann Orlov, and Oscar Handlin. Cambridge, MA: Harvard University Press.

Bleakley, Hoyt, and Aimee Chin. 2004. Language skills and earnings: Evidence from childhood immigrants. Review of Economics and Statistics 86, no. 2:481-96.

Bobo, Lawrence, James Johnson, Melvin Oliver, Reynolds Farley, Barry Bluestone, Irene Browne, Sheldon Danziger, Gary Green, Harry Holzer, Maria Krysan, Michael Massagli, and Camille Zubrinsky Charles. 2000. Multi-city study of urban inequality, 1992-1994: Atlanta, Boston, Detroit, and Los Angeles. 3rd ICPSR version. Ann Arbor, MI: Interuniversity Consortium for Political and Social Research.

Bodenhorn, Howard N. 2003. The complexion gap: The economic consequences of color among free African Americans in the rural antebellum south. In Advances in agricultural economic history, vol. 2, ed. K. D. Kauffman. Amsterdam: Elsevier Science.

Borjas, George J. 1994. The economics of immigration. Journal of Economic Literature 32, no. 4:1667-1717.

- 1995. Assimilation and changes in cohort quality revisited: What happened to immigrant earnings in the 1980s? Journal of Labor Economics 13, no. 2:201-45.

Burke, Meghan A., and David G. Embrich. 2008. Colorism. In International encyclopedia of the social sciences. 2nd ed., vol. 2, ed. William A. Darity Jr. Detroit: MacMillan Reference.

Cain, Glen G. 1986. The economic analysis of labor market discrimination: A survey. In Handbook of labor economics, vol. 1, ed. Orley Ashenfelter and Richard Layard. Amsterdam: Elsevier Science.

Card, David. 2005. Is the new immigration really so bad? Economic Journal 115, no. 507: F300-F323.

Case, Anne, and Christina Paxson. 2006. Stature and status: Height, ability, and labor market outcomes. Working Paper no. 12466, National Bureau of Economic Research, Cambridge, MA.

Cawley, John. 2004. The impact of obesity on wages. Journal of Human Resources 39, no. 2:451-74.

Chiswick, Barry R., and Paul W. Miller. 2007. The international trans- 
ferability of immigrants' human capital skills. Discussion Paper no. 2670, IZA, Bonn.

Clark, Ximena, Timothy J. Hatton, and Jeffrey G. Williamson. 2007. Explaining U.S. immigration, 1971-1998. Review of Economics and Statistics 89, no. 2:359-73.

de la Garza, Rodolfo, Angelo Falcon, F. Chris Garcia, and John A. Garcia. 1998. Latino national political survey, 1989-1990. 3rd ICPSR version. Ann Arbor, MI: Inter-university Consortium for Political and Social Research.

Ehrlich, Paul R. 1977. The race bomb. New York: Quadrangle.

Espino, Rodolfo, and Michael M. Franz. 2002. Latino phenotype discrimination revisited: The impact of skin color on occupational status. Social Science Quarterly 83, no. 2:612-23.

Fogel, Robert W., and Dora L. Costa. 1997. A theory of technophysio evolution, with some implications for forecasting population, health care costs, and pension costs. Demography 34, no. 1:49-66.

Friedberg, Rachel M. 2000. You can't take it with you? Immigrant assimilation and the portability of human capital. Journal of Labor Economics 18, no. 2:221-51.

Goldsmith, Arthur H., Darrick Hamilton, and William Darity Jr. 2006. Shades of discrimination: Skin tone and wages. American Economic Review 96, no. 2:242-45.

- 2007. From dark to light: Skin color and wages among AfricanAmericans. Journal of Human Resources 42, no. 4:701-38.

Gravlee, Clarence C., William W. Dressler, and H. Russell Bernard. 2005. Skin color, social classification, and blood pressure in southeastern Puerto Rico. American Journal of Public Health 95, no. 12:2191-97.

Hall, Ronald. 1995. The bleaching syndrome: African Americans' response to cultural domination vis-à-vis skin color. Journal of Black Studies 26, no. 2:172-84.

Hamermesh, Daniel S., and Jeff Biddle. 1994. Beauty and the labor market. American Economic Review 84, no. 5:1174-94.

Herring, Cedric. 2004. Skin deep: Race and complexion in the "colorblind" era. In Skin/deep: How race and complexion matter in the colorblind era, ed. Cedric Herring, Verna M. Keith, and Hayward Derrick Horton. Urbana: University of Illinois Press.

Hersch, Joni. 2006. Skin tone effects among African Americans: Perceptions and reality. American Economic Review 96, no. 2:251-55.

Hill, Mark E. 2002. Skin color and intelligence in African Americans: A reanalysis of Lynn's data. Population and Environment 24, no. 2:209-14.

Hirsch, Barry, and Edward J. Schumacher. 2004. Match bias in wage gap estimates due to earnings imputation. Journal of Labor Economics 22, no. 3:689-722. 
Hirschman, Charles. 2005. Immigration and the American century. Demography 42, no. 4:595-620.

Holbrook, Allyson L., Jon A. Krosnick, and Alison Pfent. 2007. The causes and consequences of response rates in surveys by the news media and government contractor survey research firms. In Advances in telephone survey methodology, ed. James M. Lepkowski, N. Clyde Tucker, J. Michael Brick, Edith D. De Leeuw, Lilli Japec, Paul J. Lavrakas, Michael W. Link, and Roberta L. Sangster. New York: Wiley.

Hughes, Michael, and Bradley R. Hertel. 1990. The significance of color remains: A study of life chances, mate selection, and ethnic consciousness among black Americans. Social Forces 68, no. 4:1105-20.

Jablonski, Nina G. 2006. Skin: A natural history. Berkeley: University of California Press.

Jablonski, Nina G., and George Chaplin. 2000. The evolution of human skin coloration. Journal of Human Evolution 39, no. 1:57-106.

Jackson, James S., and Gerald Gurin. 1997. National survey of black Americans: Waves 1-4; 1979-1980, 1987-1988, 1988-1989, 1992. Ann Arbor, MI: Inter-university Consortium for Political and Social Research.

Jasso, Guillermina. 2007. Immigration and the attack on American apartheid. Unpublished manuscript presented at the Inaugural Conference of the Center for Research on Inequalities and the Life Course, Yale University.

Jasso, Guillermina, Douglas S. Massey, Mark R. Rosenzweig, and James P. Smith. 2005. Immigration, health, and New York City: Early results based on the U.S. new immigrant cohort of 2003. FRBNY Economic Policy Review 11, no. 2:127-51.

- Forthcoming. The U.S. New Immigrant Survey: Overview and preliminary results based on the new-immigrant cohorts of 1996 and 2003. In Longitudinal surveys and cross-cultural survey design, ed. Beverley Morgan and Ben Nicholson. London: Crown.

Kasper, Henry T. 2004. Matching yourself with the world of work. Occupational Outlook Quarterly 48, no. 3:2-21.

Keith, Verna M., and Cedric Herring. 1991. Skin tone and stratification in the black community. American Journal of Sociology 97, no. 3:760-78.

Klag, Michael J., Paul K. Whelton, Josef Coresh, Clarence E. Grim, and Lewis H. Kuller. 1991. The association of skin color with blood pressure in U.S. blacks with low socioeconomic status. Journal of the American Medical Association 265, no. 5:599-602.

Klonoff, Elizabeth A., and Hope Landrine. 2000. Is skin color a marker for racial discrimination? Explaining the skin color-hypertension relationship. Journal of Behavioral Medicine 23, no. 4:329-38.

Krieger, Nancy, Stephen Sidney, and Eugenie Coakley. 1998. Racial discrimination and skin color in the CARDIA study: Implications for 
public health research. American Journal of Public Health 88, no. 9: 1308-13.

Lamason, Rebecca L., Manzoor-Ali P. K. Mohideen, Jason R. Mest, Andrew C. Wong, Heather L. Norton, Michele C. Aros, Michael J. Jurynec, Xianyun Mao, Vanessa R. Humphreville, Jasper E. Humbert, Soniya Sinha, Jessica L. Moore, Pudur Jagadeeswaran, Wei Zhao, Gang Ning, Izabela Makalowska, Paul M. McKeigue, David O’Donnell, Rick Kittles, Esteban J. Parra, Nancy J. Mangini, David J. Grunwald, Mark D. Shriver, Victor A. Canfield, and Keith C. Cheng. 2005. SLC24A5, a putative cation exchanger, affects pigmentation in zebra fish and humans. Science 310, no. 5755:1782-86.

Loh, Eng Seng. 1993. The economic effects of physical appearance. Social Science Quarterly 74, no. 2:420-38.

Lynn, Richard. 2002. Skin color and intelligence in African Americans. Population and Environment 23, no. 4:365-75.

Mason, Patrick L. 2004. Annual income, hourly wages, and identity among Mexican-Americans and other Latinos. Industrial Relations 43, no. 4:817-34.

Massey, Douglas S., Camille Z. Charles, Garvey Lundy, and Mary J. Fischer. 2003. The source of the river: The social origins of freshmen at America's selective colleges and universities. Princeton, NJ: Princeton University Press.

Massey, Douglas S., and Jennifer A. Martin. 2003. The NIS skin color scale. Office of Population Research, Princeton University.

McDowell, Margaret A., Cheryl D. Fryar, Rosemarie Hirsch, and Cynthia L. Ogden. 2005. Anthropometric reference data for children and adults: U.S. population, 1999-2002. Advance data from vital and health statistics 361. Hyattsville, MD: National Center for Health Statistics, U.S. Department of Health and Human Services.

Parra, E. J., R. A. Kittles, and M. D. Shriver. 2004. Implications of correlations between skin color and genetic ancestry for biomedical research. Nature Genetics 36, no. 11: S54-S60.

Persico, Nicola, Andrew Postlewaite, and Dan Silverman. 2004. The effect of adolescent experience on labor market outcomes: The case of height. Journal of Political Economy 112, no. 5:1019-53.

Race, Ethnicity, and Genetics Working Group, National Human Genome Research Institute. 2005. The use of racial, ethnic, and ancestral categories in human genetics. American Journal of Human Genetics 77, no. 4:519-32.

Russell, Kathy, Midge Wilson, and Ronald Hall. 1992. The color complex: The politics of skin color among African Americans. New York: Harcourt Brace.

Schultz, T. Paul. 2002. Wage gains associated with height as a form of health human capital. American Economic Review 92, no. 2:349-53. 
Steckel, Richard H. 1995. Stature and the standard of living. Journal of Economic Literature 33, no. 4:1903-40.

Thomas, Duncan, and John Strauss. 1997. Health and wages: Evidence on men and women in urban Brazil. Journal of Econometrics 77, no. 1:159-85.

Timmons, Heather. 2007. Telling India's modern women they have power, even over their skin tone. New York Times, May 30.

U.S. General Accounting Office. 1990. Immigration reform: Employer sanctions and the question of discrimination. Washington, DC: U.S. General Accounting Office.

Wolf, Susan M. 2006. Debating the use of racial and ethnic categories in research. Journal of Law, Medicine, and Ethics 34, no. 3:483-86. 